PECEREO AY. TIC DEC $2: \mathrm{i}$

NUREG/CR-0998

\title{
MASTER
}

\section{Technical Manual Operation and Equipment Instructions For In Situ Impulse Test}

Shannon \& Wilson, Inc. and Agbabian Associates

Prepared for

U. S. Nuclear Regulatory

Commission 


\section{DISCLAIMER}

This report was prepared as an account of work sponsored by an agency of the United States Government. Neither the United States Government nor any agency Thereof, nor any of their employees, makes any warranty, express or implied, or assumes any legal liability or responsibility for the accuracy, completeness, or usefulness of any information, apparatus, product, or process disclosed, or represents that its use would not infringe privately owned rights. Reference herein to any specific commercial product, process, or service by trade name, trademark, manufacturer, or otherwise does not necessarily constitute or imply its endorsement, recommendation, or favoring by the United States Government or any agency thereof. The views and opinions of authors expressed herein do not necessarily state or reflect those of the United States Government or any agency thereof. 


\section{DISCLAIMER}

Portions of this document may be illegible in electronic image products. Images are produced from the best available original document. 


\section{NOTICE}

This report was prepared as an account of work sponsored by an agency of the United States Government. Neither the United States Government nor any agency thereof, or any of their employees, makes any warranty, expressed or implied, or assumes any legal liability or responsibility for any third party's use, or the results of such use, of any information, apparatus product or process disclosed in this report, or represents that its use by such third party would not infringe privately owned rights. 


\section{Technical Manual Operation and Equipment Instructions for In Situ Impulse Test}

Manuscript Completed: June 1977

Date Published: November 1979

Shannon \& Wilson, Inc. and Agbabian Associates

Seattle - El Segundo

Prepared for

Division of Reactor Safety Research

Office of Nuclear Regulatory Research

U.S. Nuclear Regulatory Commission

Washington, D.C. 20555

NRC FIN No. B3015 


\section{ABSTRACT}

This manual describes the test equipment and procedures for a new field test which determines the shear modulus of a soil deposit at strain levels equivalent to those experienced during actual earthquakes. Results from this test are typically used as input parameters to response analyses for evaluating local soil effects during earthquake shaking.

The test employs a cross-hole wave propagation procedure with velocity transducers located in closely spaced adjacent borings. Clear, consistent and repeatable data in all types of soil and a method of data reduction different from conventional geophysical "first arrival" techniques are unique aspects of this new test. In addition to describing the principles of the test and data reduction procedures, major discussions of the field procedures are also included. Detailed drilling and testing information is provided both for planning and executing a test program.

The limitations of the test are also discussed. Four major factors affecting the accuracy of the test or limiting the capability of the test are considered and include 1) the capabilities of the drilling equipment, 2) the accuracy of the measurements, 3) the applicability of the computational theory, and 4) the effects of variations between the assumed and real conditions. 

1. INTRODUCTION 1

$1.1 \quad$ Purpose and Scope 1

1.2 Authorization and Project Personnel 1

1.3 Report Organization 2

2. DESCRIPTION OF THE TEST

2.1 Principles of the Test

2.2 Parameters Measured 3

2.3 Data Reduction Procedures $\quad 8$

3. TEST LIMITATIONS 14

3.1 Drilling Limitations 14

3.2 Measurement Limitations 16

3.3 Limitations of Computational Theory 17

3.4 Effects of Variations from Assumed Conditions

4. TEST EQUIPMENT $\quad 21$

4.1 Anchor and Hammer Assembly 21

4.1.1 Hydraulic Anchor System $\quad 21$

4.1.2 Pneumatic Anchor System $\quad 27$

4.2 Sensing Equipment $\quad 31$

4.3 Recording Equipment 33

$\begin{array}{lll}4.4 & \text { Surveying Equipment } & 38\end{array}$

5. FIELD CONSIDERATIONS AND PROCEDURES

5.1 Drilling Considerations $\quad 41$

5.2 Testing Considerations $\quad 45$

5.3 Field Drilling and Casing Installation Procedures 47

$\begin{array}{lll}5.4 & \text { Surveying Procedures } & 49\end{array}$

5.5 In Situ Test Procedures

6. FIELD EQUIPMENT MAINTENANCE AND REPAIR $\quad 59$

6.1 Hydraulic Anchor Assembly $\quad 59$

6.2 Pneumatic Anchor Assembly 61

6.3 Sensors and Sensor Holders $\quad 62$

6.4 Recording Equipment $\quad 64$

REFERENCES $\quad 66$ 


\section{List of Figures}

Figure

Description

Page

2.1 Schematic representation of insitu impulse test method

2.2 Typical velocity-time signatures displayed on the screen of the oscilloscope

2.3 Velocity-time signatures in soil and rock 6

2.4 Time of arrival of first zero crossing vS distance 9 from anchor

2.5 Example plot of modulus and velocity versus strain 12

2.6 Schematic representation of typical in situ test results

3.1 Plans at three sites showing drift of borings with depth

4.1 Hydraulic anchor details 22

4.2 Hammer assembly (hydraulic anchor) . 24

4.3 Curves for determining stress on soil at anchor 26 contact face

4.4 Pneumatic anchor details $2 \mathcal{C}$

4.5 Hammer assembly (pneumatic anchor) 30

4.6 Velocity sensors and holder 32

4.7 Anchor velocity sensors 34

$\begin{array}{lll}4.8 & \text { Recording console } & 35\end{array}$

$\begin{array}{lll}4.9 & 39\end{array}$ 
TECHNICAL MANUAL

\section{OPERATION AND EQUIPMENT INSTRUCTIONS}

FOR IN SITU IMPULSE TEST

\section{INTRODUCTION}

\subsection{PURPOSE AND SCOPE}

One of the more important soil parameters needed to evaluate local soil effects during large earthquakes is the dynamic shear modulus. The dynamic shear modulus of a soil varies as a function of shear strain. Strong ground motion earthquakes may produce shear strains in the range of $10^{-3}$ to $10^{-1}$ percent. Consequently, an accurate representation of a soil deposit requires the determination of material properties within this strain range.

A new in situ impulse test has been developed which satisfies this requirement. This manual provides detailed operation and equipment instructions for performing this field test at depth and interpreting the results. The procedures and equipment for this test have been developed through both field testing and analytical support studies. Field tests were accomplished initially in shallow borings, and a large test fill, and finally in deep borings at 11 sites. Analytical studies, including closed form solutions and finite element analyses of the test setup and test variables, were performed to refine the design of the equipment and to evaluate data interpretation procedures. The more significant results from these studies are presented in SW-AA, 1975a. Actual test results at production sites in a wide variety of materials are presented in SW-AA, 1974, $1975 \mathrm{~b}, 1976$ and 1977.

\subsection{AUTHORIZATION AND PROJECT PERSONNEL}

The study was conducted by a joint venture of Shannon and Wilson, Inc. and Agbabian Associates (SW-AA) under the sponsorship of the U.S. Nuclear Regulatory Commission (NRC). Dr. J. Harbour served as technical monitor for the NRC on this project. This work was authorized by Contract No. AT(49-24)-0200 and represents part 
of an overall project for determining the best methods to evaluate and predict the earthquake ground response at potential nuclear power plant sites.

A number of persons from the joint venture assisted in conducting those analytical and experiental studies which led to the development of the test. For Shannon \& Wilson, Messrs. F. R. Brown and.J. H. Troncoso were the prinripal investigators. Mr. Brown was largely responsible for the organization and preparation of this manual. Mr. S. D. Wilson served as a general consultant providing guidance throughout all phases of the work. Dr. R. P. Miller was the Project Engineer for Shannon \& Wilson and is also the Project Manager for the joint venture. For Agbabian Associates, Mr. S. D. Werner was the Project Engineer assisted by Messrs. D. Van Dillen, K. Bosen, D. G. Yates and K. T. Dill. Dr. Lydik S. Jacobsen, special consultant to the joint venture, also provided valuable guidance in these studies.

\subsection{REPORT ORGANIZATION}

The report is divided into six sections. Sections 2 and 3 , which follow, describe the principles of the test including data reduction and the main limitations of the test. The actual equipment used in the field is described and illustrated in Section 4. The practical considerations for planning and executing a field test are discussed in Section 5. Finally, Section 6 covers maintenance and repair of the field equipment. 


\section{DESCRIPTION OF THE TEST}

\subsection{PRINCIPLES OF THE TEST}

The in situ impulse test is similar to conventional cross-hole geophysical techniques in that both methods are based on the horizontal propagation of shear waves. The main difference between the two tests is the level of shear strain attained in the field. The test layout of the in situ impulse test is shown in Figure 2.1. It includes an in-hole generating source and three or more recording stations (each containing one vertically oriented velocity sensor). The recording stations are positioned in cased or uncased vertical boreholes at the same depth as the generating source.

The primary difference between this test and other cross-hole impulse type tests is in the spacing of the holes and the generation and control of the shear waves. The desired larger strain amplitudes in this test are obtained by locating the soil response sensors in boreholes positioned close to the energy source. Typical distances from the source to the various sensors are 4, 8 and 16 feet. The other distinct feature of this test is that the shear wave consists of a controlled, single-pulse rather than a more complex train of body waves. The resulting velocity-time signatures (Figure 2.2) have similar but distinct shapes at each recording station. The similarity in wave shape allows selection of a point on the wave pattern, such as the zero crossing, to mark the arrival time of the wave at the station. Tests at different sites have shown that the shapes are not only consistent and predictable for most soil and rock types (Figure 2.3), but also that each signature can be nearly identically reproduced at a given depth.

\subsection{PARAMETERS MEASURED}

In order to determine the shear velocity (and thus the modulus) variation with strain, six basic measurements are obtained at regular depth intervals in the normal performance of the test. These include: 


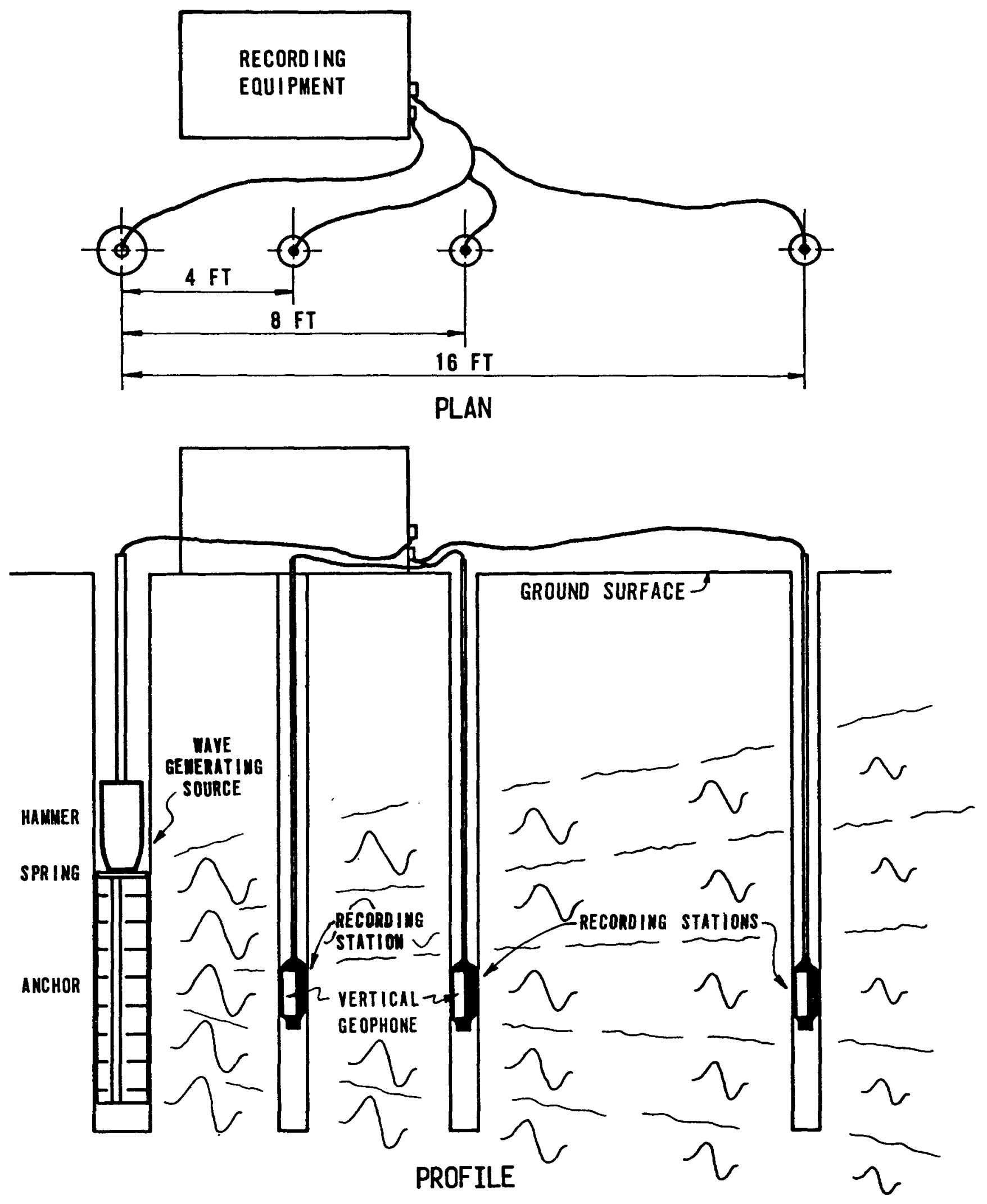

FIGURE 2.1 SCHEMATIC REPRESENTATION OF INSITU IMPUL.SE TEST METHOD 

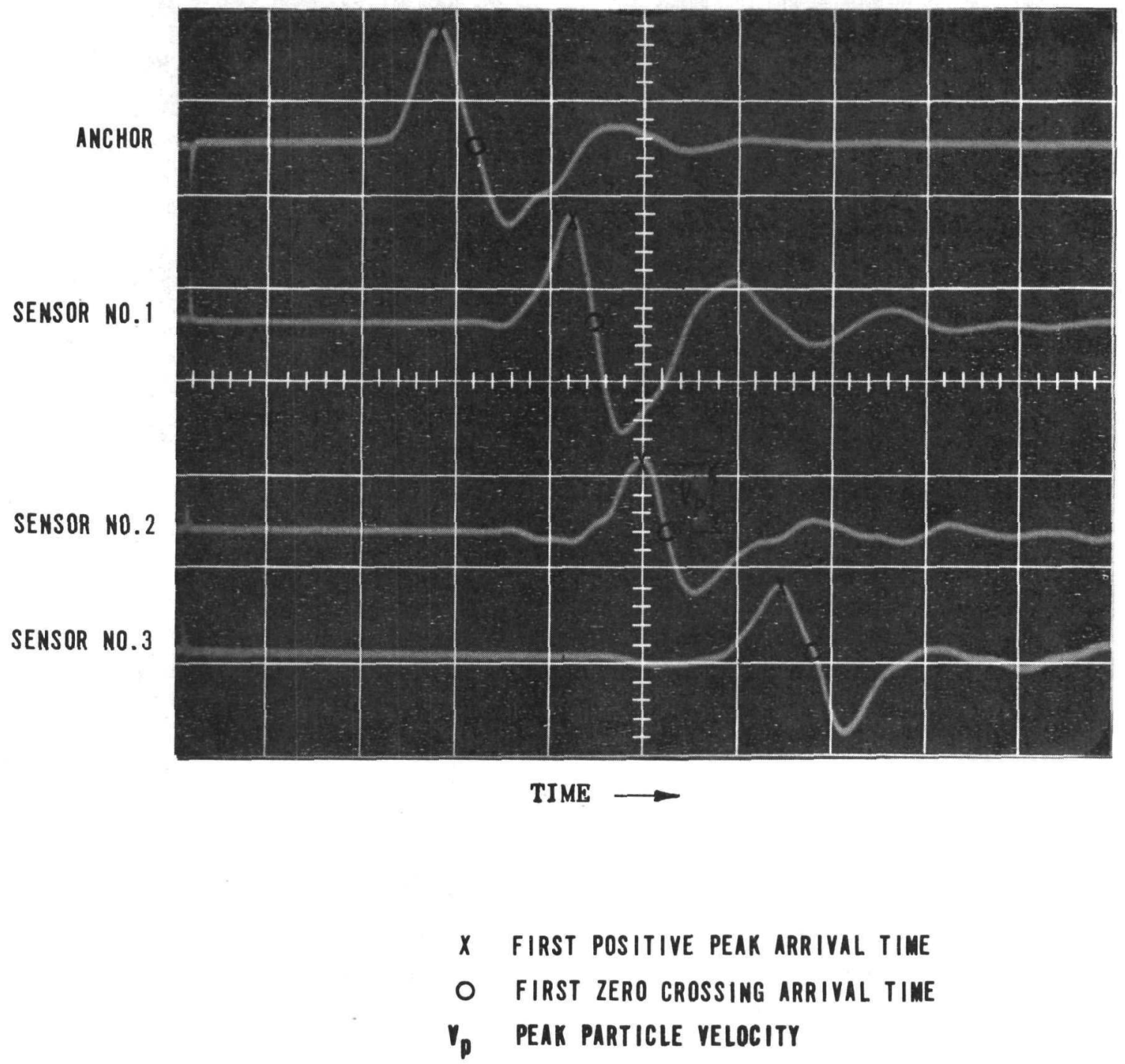

FIGURE 2.2 TYPICAL VELOCITY-TIME SIGNATURES DISPLAYED ON THE SCREEN OF THE OSCILLOSCOPE 


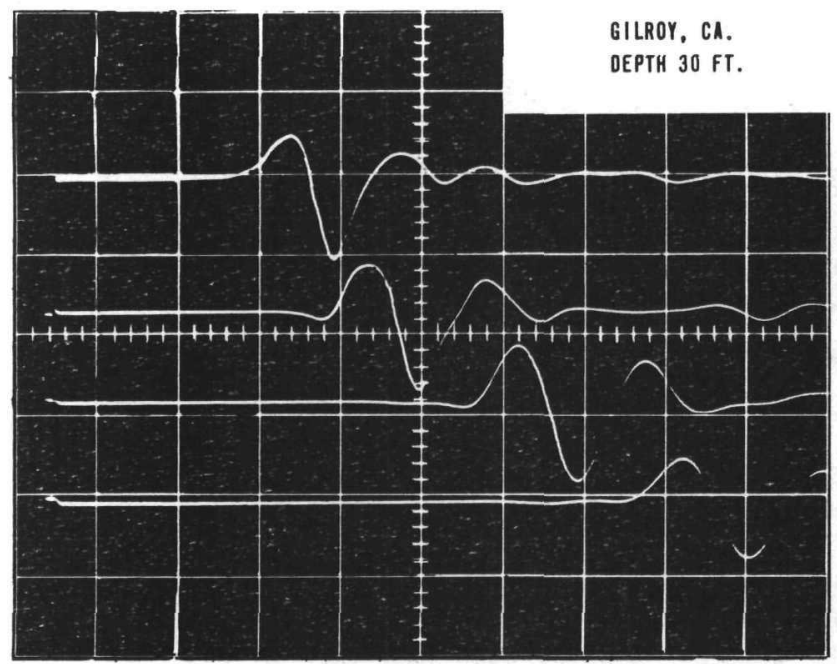

(A) DATA IN CLAY

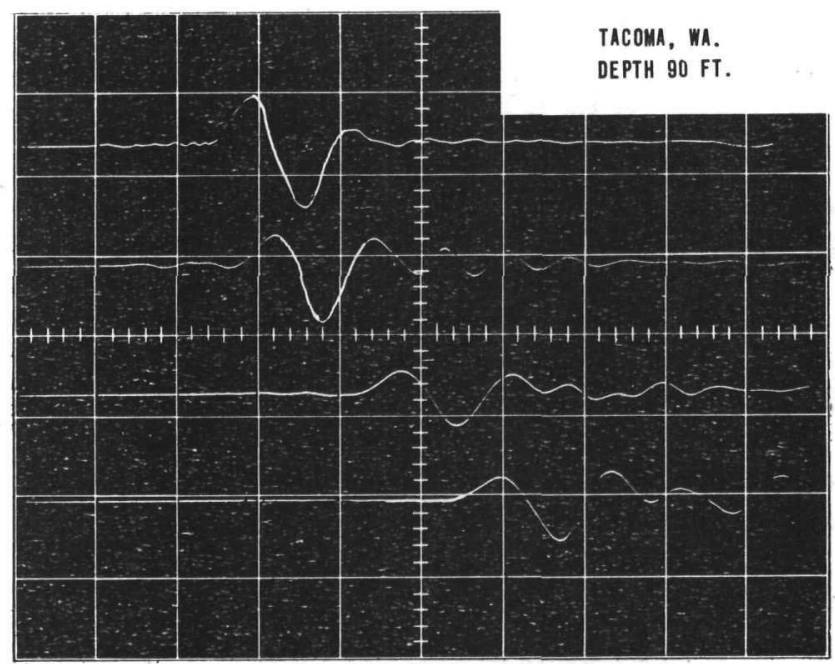

(C) DATA IN GRAVEL

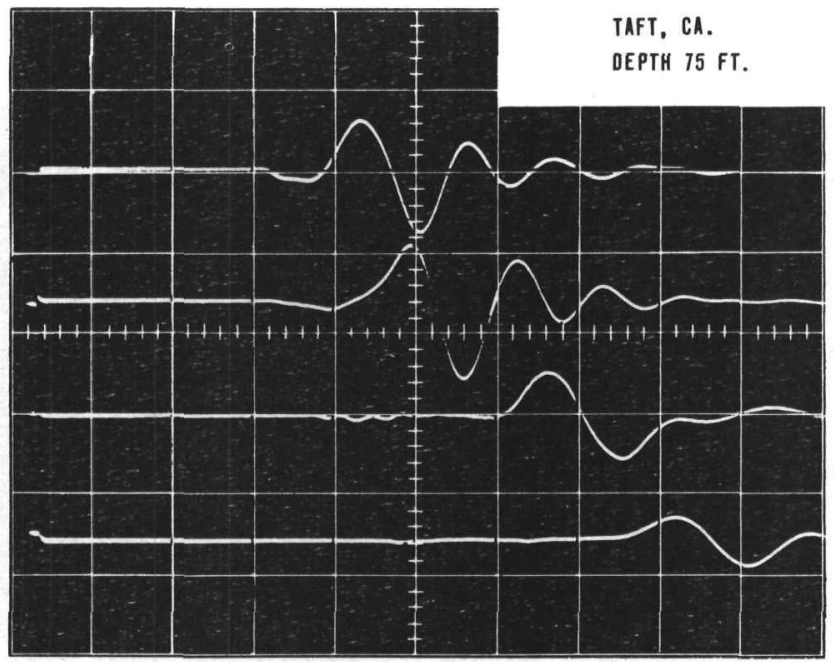

(B) DATA IN SAND

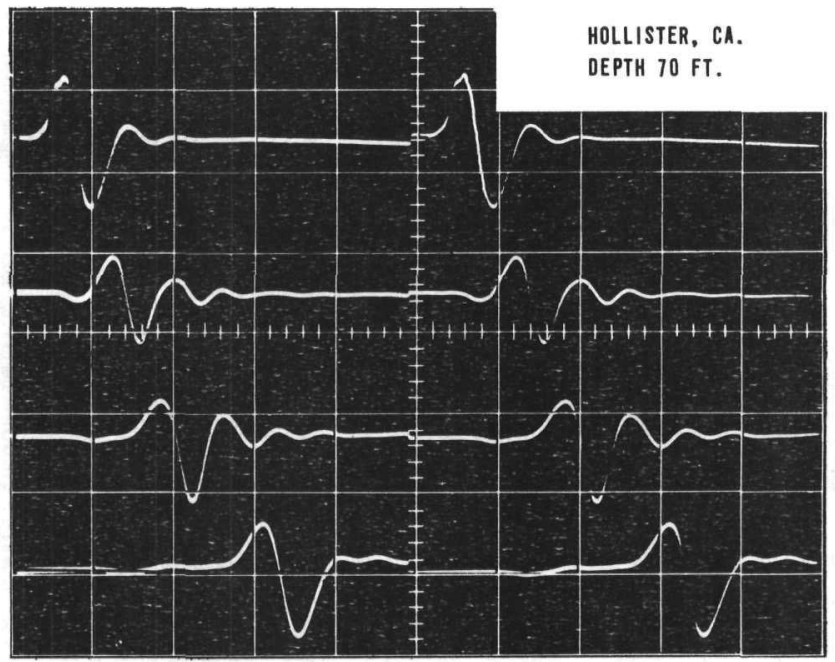

(D) DATA IN ROCK*

* odta is being displayed on an oscilloscope frou a menerr cami in TME ReconeIme ststen. THE TIEe SCALE ON THIS RECORD IS SET SUCH THAT EACH SIGMAL IS BEING REPEATED (OR DISPLAYED TIICE). 
1) Time history records of vertical and horizontal particle velocity

2) Arrival time at each sensor of a specific point on the wave

3) Distances between the anchor and the free field sensors

4) Peak vertical particle velocity at each sensor

5) Jacking pressure applied to the energy source

6) Diameter of the energy source

The time histories are usually recorded in both analog (oscilloscope display) and digital form (computer tape). The digital data provides better resolution and are used as the primary source for determining arrival time. Normally computers are used to print the data and to read and extract the time points of interest.

Previous studies (SW-AA, 1975a) have shown that the best points on the records for determining the arrival times at each vertically oriented sensor correspond to either the first positive peak $(x)$ on the largest velocity pulse or the first zero crossing point (o) following this peak (Figure 2.2). It is preferable to use the zero crossing point because it occurs after peak strain has developed and is more sharply identified since it corresponds to a time when the velocity is changing rapidly. The peak velocity point is occasionally difficult to define precisely because the velocity change (acceleration) is zero and therefore the arrival time is strongly influenced by minor distortions caused by imperfections in the signature.

The distance between borings at corresponding depths is determined by precise in-hole surveys. This is accomplished by lowering an inclinometer into each hole to measure horizontal drift with depth relative to the ground surface. This data is then combined with the distances measured between borings at the ground surface to compute the distances between holes at all corresponding depths. The detailed procedures for accomplishing these measurements are described in Section 5 . High precision in these measurements is required to assure accurate computation of shear wave velocities for such closely spaced borings. 
Time histories of horizontal particle velocity are also obtained at each recording station. These records are used to compute the compressional wave velocity of the soil. Also, these measurements are used as a check of the field surveyed distances. Arrival times of the compressional wave plotted versus the survey distance between holes at a given depth will produce a straight line for a uniform soil deposit. The slope of this line corresponds to the compression wave velocity at low strain levels. If one plotted point does not fall on this line, the survey data of this hole or recording station can be reviewed for computational errors or possible effects of spiraling of the survey casing. This additional source for checking hole distances provides confidence that distances have been correctly established.

The fourth parameter, peak vertical particle velocity, $\left(V_{p}\right.$ in Figure 2.2), is obtained directly from the time history measurements at each station. For these measurements, the amplification applied to the transducers for each station must be known and recorded independently for each test. Test labels containing the amplification factors for each sensor can be manually placed on the computer tapes prior to recording the time history data for each test. These factors can then be recalled by the computer and applied to the time history data to determine the vertical particle velocity at any time.

The final two parameters, the jacking pressure and the diameter of the energy source or anchor assembly, are determined at each test depth from measurements made at the ground surface. These values are used for computing the stress in the soil surrounding the energy source and for empirically adjusting the shear wave velocity computed near the source.

\subsection{DATA REDUCTION PROCEDURES}

Having determined the above parameters, the time data are next plotted versus distance as shown in Figure 2.4. This curve is constructed using the wave arrival times (zero crossing point) at each sensor and the horizontal distance between holes obtained from the survey measurements. The slope of this curve at each sensor is determined graphically and corresponds to the shear wave velocity at that station. 


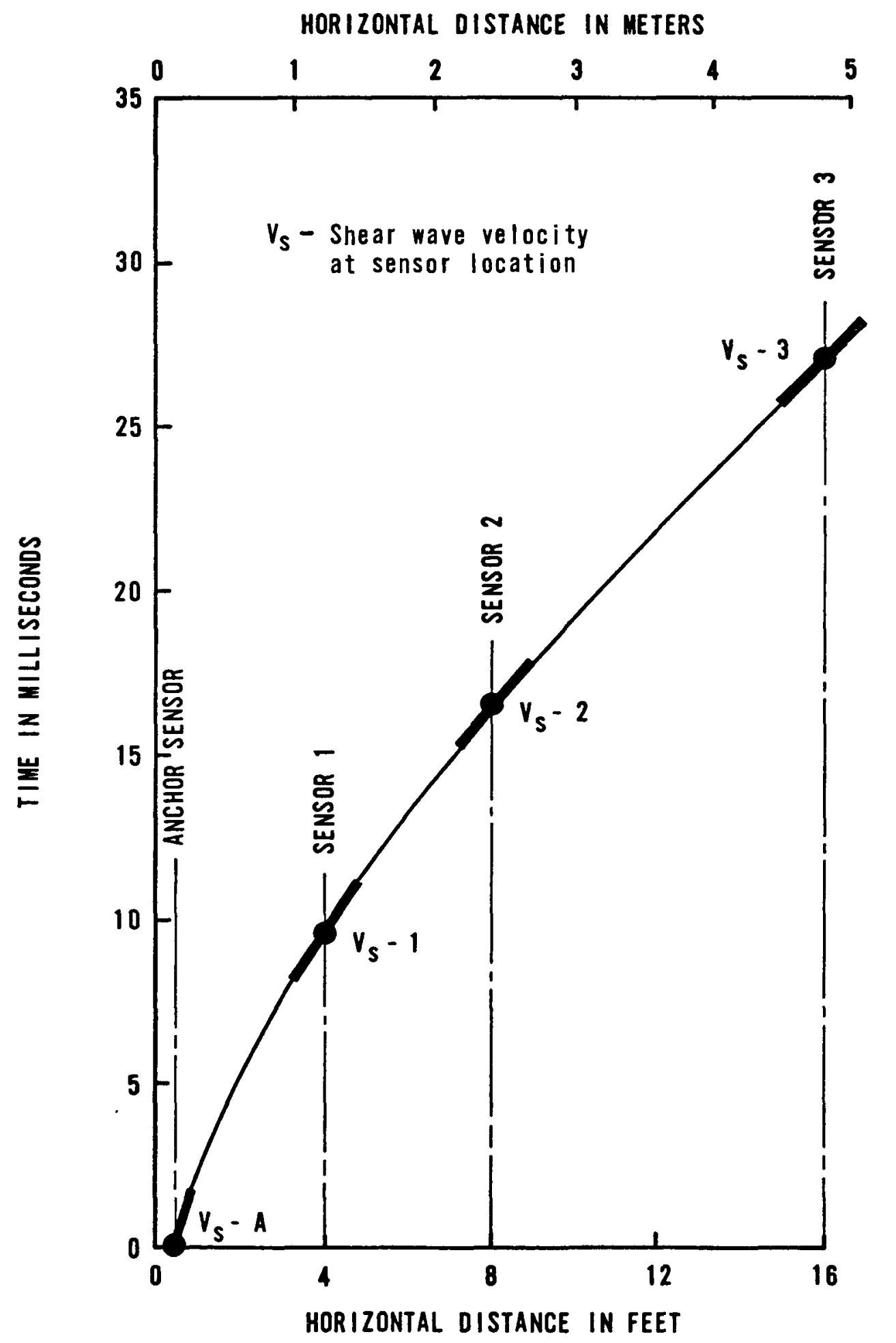

FIGURE 2.4 TIME OF ARRIVAL OF FIRST ZERO CROSSING VS BISTANCE FROM ANCHOR 
The amplitude of the shear pulse, which corresponds to the peak shear strain, decays rapidly with distance. The peak shear strain at each sensor location is computed assuming the wave travels as a plane wave. This results in the following expression for the peak shear strain, $\gamma$ :

$$
\gamma=\frac{V_{P}}{V_{S}}
$$

where,

$$
\begin{array}{ll}
v_{P}= & \text { Peak particle velocity amplitude } \\
v_{S}= & \text { Shear wave velocity }
\end{array}
$$

The procedures for determining the shear wave velocity and strains at the energy source have been developed empirically and are not straightforward (SW-AA, 1975a). The shear wave velocity at the energy source, determined from Figure 2.4 (the zero crossing point), generally represents an upper bound value and must be adjusted downward. Factors affecting this measurement are discussed in Section 3.4. The strains at the anchor must be computed using one of three approximate procedures depending primarily upon the degree of coupling of energy source (anchor) with the borehole walls.

The use of casing in the sensor holes alters wave arrival times and requires that correction factors be applied to the data. As an example, arrival times should be reduced by about 0.4 milliseconds in holes that have schedule 40 plastic casing. Casing correction factors and test limitations are further discussed in Section 3 and SW-AA, $1975 \mathrm{a}$.

Having determined the shear wave velocity and corresponding peak shear strain for each station, the shear moculus, G, at each depth is computed by

$$
\mathrm{G}=\rho \mathrm{V}_{\mathrm{s}}^{2}
$$


where $\rho$ is the mass density of the soil. Both $G$ and $V_{S}$ are then plotted versus strain, as shown in Figure 2.5. This procedure is repeated at a regular depth interval producing a family of curves. From these combined data, profiles of the variation in shear modulus or velocity at specific strain levels can be prepared for the entire soil deposit (Figure 2.6). These profiles can be used to obtain soil material properties for use as input to site response studies. 


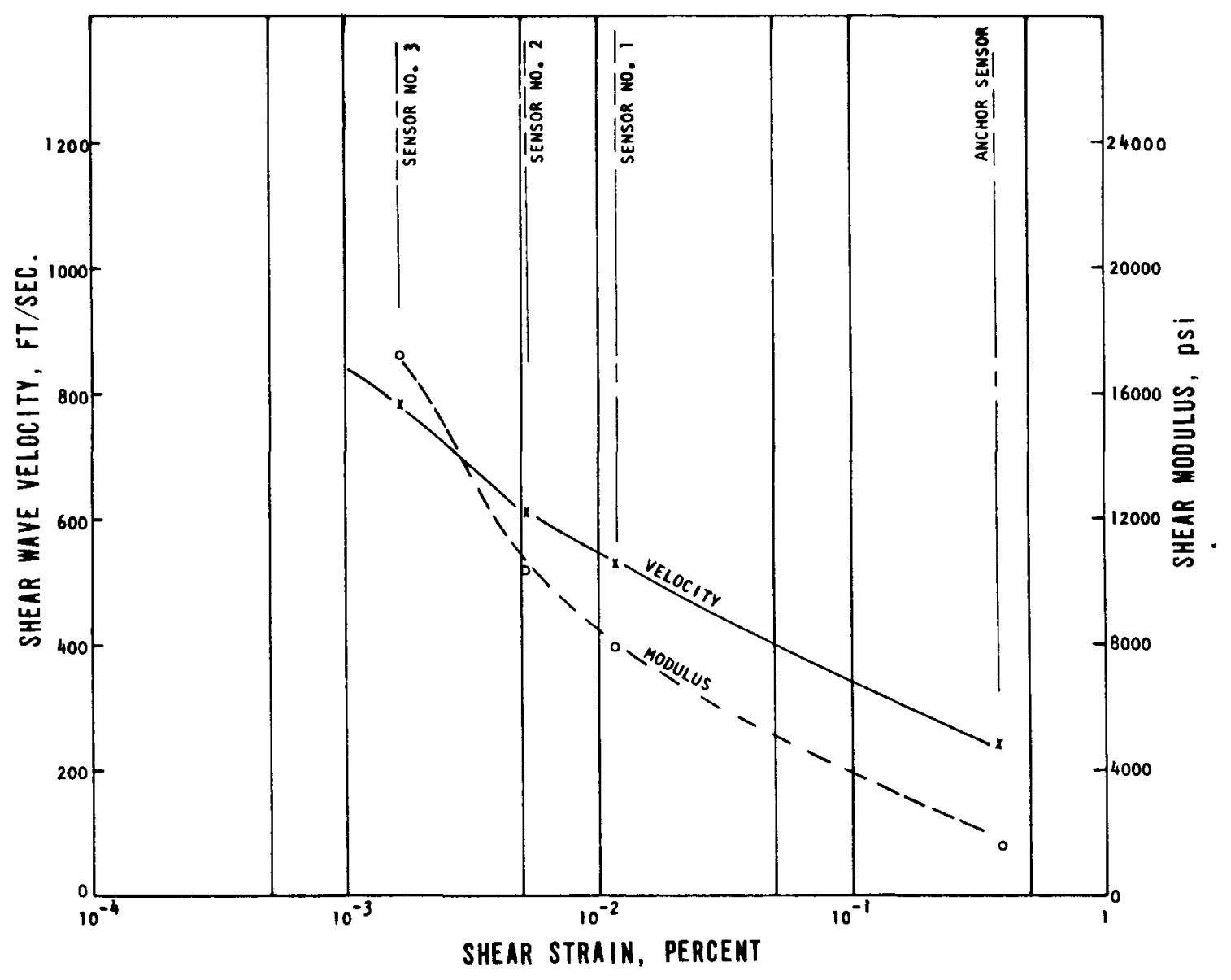

FIGURE 2.5 EXAMPLE PLOT OF MODULUS AND VELOCITY VERSUS STRAIN 


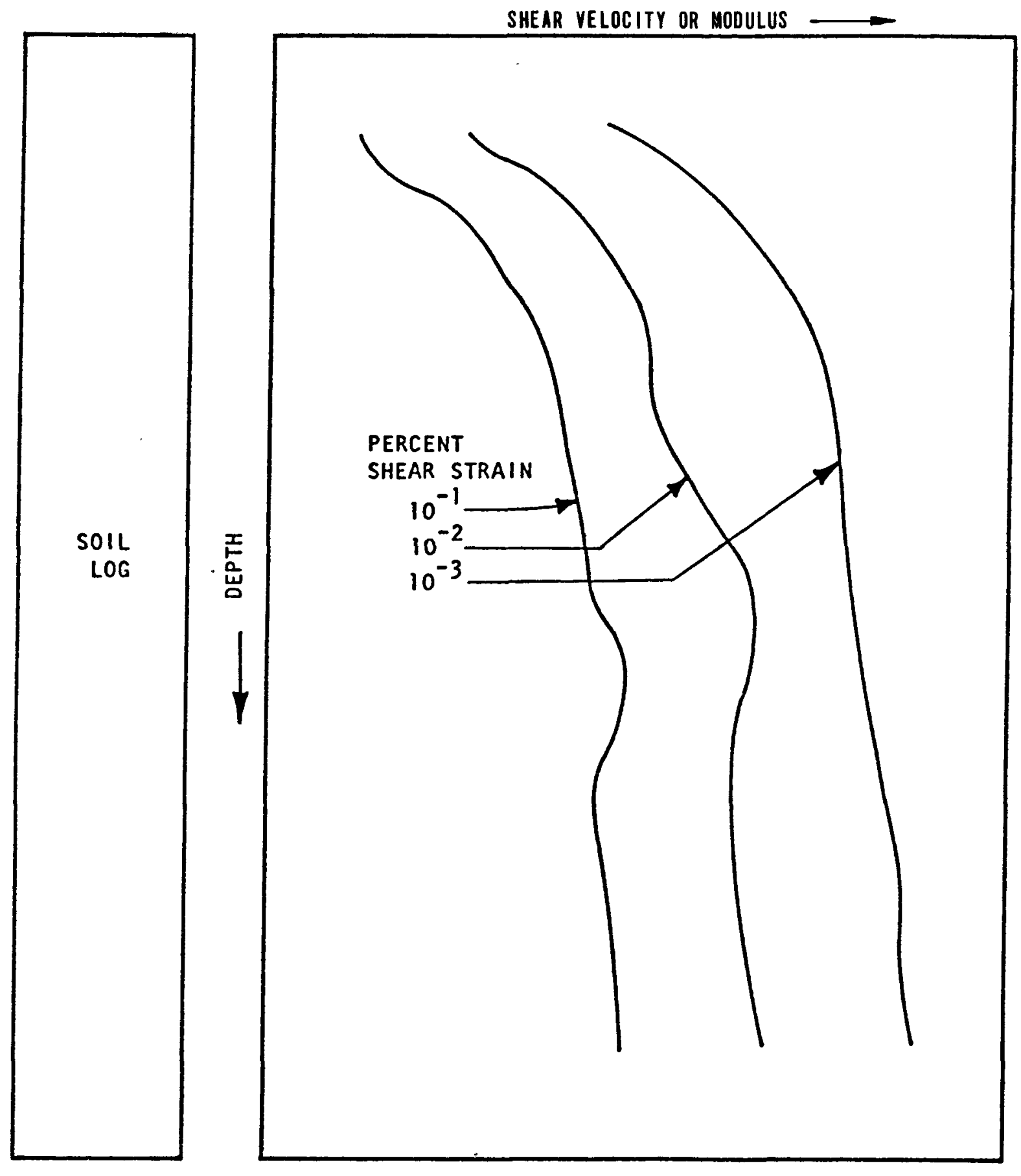

PIGURE 2.6 SCHEMATIC REPRESENTATION OF TYPICAL IN SITU TEST RESULTS 


\section{TEST LIMITATIONS}

As in any field or laboratory test, most tests have certain requirements, procedures, or limitations which affect the accuracy and repeatability of the results or affect the general range or capability of the test. The reliability of the in situ test is controlled by four major factors: 1) the capability of drilling equipment, 2) the accuracy of the measurements, 3) the applicability of the computational theory, and 4) the effects of variations between the assumed and real conditions.

\subsection{DRILLING LIMITATIONS}

The most critical limitations associated with drilling and with the entire test program involve hole verticality and spacing. Both of these factors affect the quality of the data and the range of strains achieved in the field.

Hole verticality or drift is critical in that closely spaced holes that approach each other with depth effectively result in one recording station rather than two. This is significant when considering that most soil borings have an average vertical drift of about 1 to 6 percent. Conceivably, holes spaced 4 feet apart at the ground surface could connect at a depth of 100 to 200 feet. Typical borehole drift measured at three test sites is shown in Figure 3.1. Although special care was exercised to maintain hole verticality, a random drift of up to 4 feet is evident in the 90 - to 140 -foot borings. The use of drill collars helped to minimize the drift but did not eliminate it.

Due to the problem of hole drift, it is only feasible to conduct the test to depths generally less than about 200 feet when using minimum hole spacings of 3 to 4 feet. There is also the risk that these holes may become interconnected hydraulically through some highly pervious zone. 

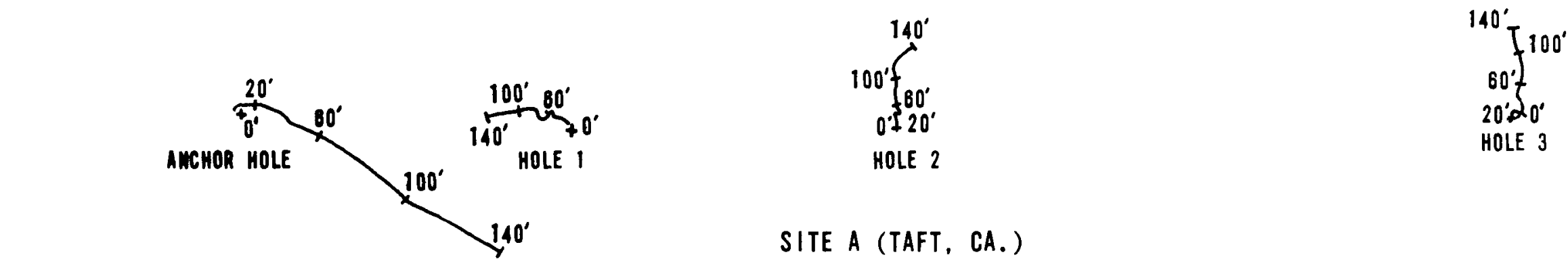

SITE A (TAFT, CA.)

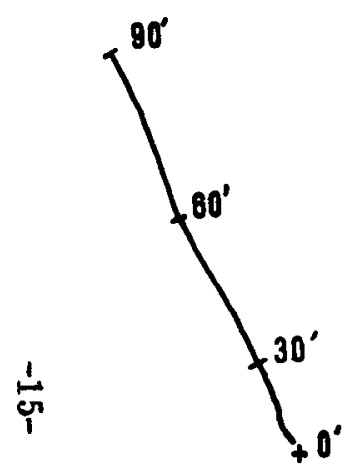

ANCHOR MOLE

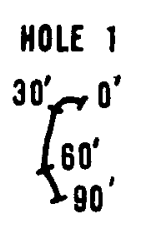

HOLE 2

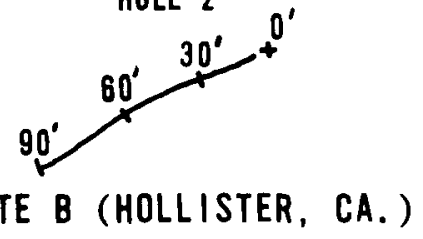

$60^{\prime} f^{90^{\prime}}$

HOLE 3
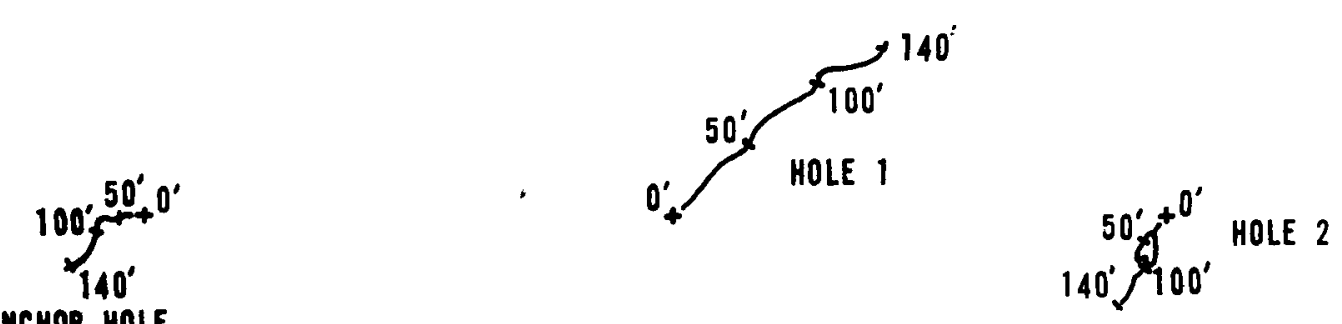

SITE C (EL CENTRO, CA)

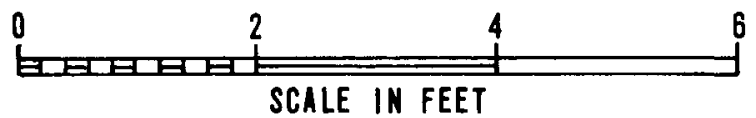

FIGURE 3.1 PLANS AT THREE SITES SHOWING DRIFT OF BORINGS WITH DEPTH 
Hole spacings also limit and control the range of strains that can be obtained in the free field soils. Typical shear strains computed for most soils with sensors spaced at 4,8 and 16 feet from the energy source (Figure 2.1 ), range from $10^{-4}$ to $2 \times 10^{-2}$ percent. The actual values obtained depend largely upon the stiffness of the soil. Smaller strains are usually achieved in stiffer soils with typical free field values for rock ranging between $10^{-4}$ to $10^{-5}$ percent. Consequently, decreasing the hole spacing will result in larger shear strains. However, holes spaced at a close interval have a high probability of interconnecting, either physically or hydraulically. This may result in the loss of one or more holes.

Achieving larger strains, in the order of $10^{-1}$ percent, may also be obtained by incorporating the velocity time record obtained at the energy source. Special field tests and analytical calculations were conducted in previous efforts (SW-AA, 1975a) to establish empirical procedures for incorporating this data and obtaining reasonable estimates of shear wave velocity, however, these procedures have not been verified for all types of soils and varying test conditions. The limitations of this procedure are discussed further in Section 3.3.

\subsection{MEASUREMENT LIMITATIONS}

The second factor which could limit the reliability of the test is the accuracy of the measurements. Those parameters normally measured as a part of the test and the average estimated accuracy or resolution of these measurements are indicated below.

\section{Parameter}

1) Times of arrival

2) Distances between borings at depth

3) Peak vertical velocities

4) Jacking pressures applied to the energy source

(pneumatic)

(hydraulic)

5) Diameter of the energy source

\section{Estimated Accuracy}

.01 to $.05 \mathrm{msec}$

$\sim \pm 1$ inch

1 part in 1,000

$$
\begin{aligned}
& \pm 20 \text { psi } \\
& \pm 100 \text { psi } \\
& \pm \frac{1}{4} \text { inch }
\end{aligned}
$$


All of the above parameters apparently can be measured with sufficient accuracy and thus are no serious limitations to the test procedures provided adequate care and precaution are exercised when conducting the tests. Special equipment and procedures, described in Sections 4 and 5, are required, however, to achieve this level of accuracy.

One of the most essential parameters which is difficult to accurately measure is the distance between the borings. These measurements are obtained using special survey techniques described in Section 5. The survey measurements are routinely checked against the horizontal time history records (compressional wave velocities) as described in Section 2.2.

'The accuracy of the survey measurements is controlled by the void space that exists between the borehole walls and the temporarily installed casing needed for accomplishing the survey. The diameter of the casing is generally 3.3 inches while that of the uncased borehole is often 1 inch larger. One way to improve this accuracy is to grout a permanent casing in each hole and then survey this hole by inserting a temporary smaller-diameter slotted casing (generally $1 / 8$ inch smaller). While this procedure may improve the accuracy of the survey appreciably, the introduction of casing and grout effects require that correction factors be applied to the arrival times and peak vertical velocities. Rather than incorporate these correction factors, it is considered better to work in uncased holes and accept this 1-inch limitation on accuracy in distance measurements.

\subsection{LIMITATIONS OF COMPUTATIONAL THEORY}

Another major factor affecting the results and limitations of the in situ test is the applicability of the computational theory. The limitations of the computational theory (data-interpretation procedure) are discussed in detail in SW-AA, 1975a. The results of these and other studies (Werner and Van Dillon, 1977) as well as experimental testing have shown that valid free field shear wave velocities and the corresponding shear strains at each station are obtained using the in situ impulse test. 
One limitation of the computational theory is an assumed perfect coupling of the sensor in the borehole. Inadequate coupling of the sensors will result in a lower vertical particle velocity of the sensor as compared with the free field velocity and thus lower computed strains than truly exist. However, the field coupling and recording check procedures (Section 5.5) and the extreme clarity of the recorded pulse minimize this possibility.

Another limitation of the computational theory is the assumption that the velocity time history at the energy source (anchor sensor) represents that of the soil adjacent to the anchor. The validity of this assumption is affected by the following factors. First, the anchor sensor is positioned on one part of the anchor, a complex semi-rigid unit. Therefore, the record obtained represents the motion of only that part of the anchor and not necessarily the average motion of the anchor itself or of the surrounding soil. Secondly, the velocity time record is affected by slippage at the soil/anchor interface and may not actually represent free field movement of the soil. Finally, it is expected that the large horizontal stresses imparted to the soil by the expanded anchor will influence the velocity time records and may not be representative of free field conditions. All of these factors influence the velocities and strains computed at the anchor location.

In an attempt to account for these factors, special empirical procedures were developed (SW-AA, 1975a) for estimating the shear wave velocity and strain at the energy source. These procedures may not be applicable in all cases, and test results should be interpreted accordingly. This is not a major limitation of the test since these factors do not affect the measurements at the free field sensors, which have recorded strains as high as $10^{-2}$ percent. So even neglecting the anchor measurement, this is still quite an improvement over conventional geophysical test methods. 


\subsection{EFFECTS OF VARIATIONS FROM ASSUMED CONDITIONS}

The procedures for this test (as in most in situ geophysical tests) assume that the material properties in the immediate test area are reasonably uniform and unaltered by the drilling and testing operation. Departures from these simplified conditions, including soil discontinuities, high velocity layers, hole positions and hole disturbance, all affect the interpretation of the test results.

Local discontinuities or non-uniformities between holes could significantly affect the interpretation at any test depth. Comparisons of data above and below the depth of the suspected discontinuity will help to identify its existence. The existence of a discontinuity will distort the time-distance plot, shown in Figure 2.4. The resulting data is of limited use since the shear wave travels through dissimilar materials and does not provide a complete, accurate representation of any one soil.

Wave refraction is a problem at sites that have thin, high-velocity soil layers or where softer soils directly overlie rock. In both instances, the recordings at the sensor borings are affected in that refracted waves travelling through the higher velocity materials reach the sensors before non-refracted waves. This results in higher shear wave velocities (and moduli) being calculated than had the wave not refracted. This effect is more pronounced where there is a great velocity difference between strata, as in soil overlying rock. Outlying sensor borings are affected the most. This problem of refracting waves becomes especially noticeable when sensors are positioned more than 25 feet from the energy source. When such cases are evident, the time data from the more distant sensors should be disregarded.

Another variation from the assumed test conditions is the alteration of the site due to the borings. It is conceivable that lining all the borings in a vertical plane (Figure 2.1) may affect the test results than had the borings been positioned differently. This is known as a shadow effect. This condition was studied (SW-AA, 1975a) and it was concluded that shadow effects have negligible influence on the test results. Also, stress relief in the ground caused by the boring represents a variation from the assumed 
conditions. Theoretical relationships presented in SW-AA, 1975a, indicate that the plastic zone from stress relief around a borehole is of the same order of thickness as the hole diameter. For a 9- or 10-inch anchor hole, these disturbances may cause a minor difference in test results. The difference, however, is probably well within the range of accuracy of the results noted previously. Fortunately, the high radial jacking stress necessary for providing good anchor coupling compensates slightly, making the soils in the disturbed plastic region denser or stiffer and thus more representative of the surrounding undisturbed material.

Finally, the area around the boring may be disturbed or altered in the drilling operation. The amount of disturbance depends on the size of the hole, the properties of the materials, the drilling equipment and procedures, and the experience of the driller. There is generally little documented information on the degree of disturbance of borehole walls. However, the zone of disturbance in most soils (except possibly gravels) can probably be confined to a thickness of 1 to 2 inches using care in the drilling. This thickness is estimated to have a negligible affect on the test results since both sensors and the anchor usually penetrate or displace these softer disturbed materials to achieve firm coupling. 


\section{TEST EQUIPMENT}

Equipment for performing the impulse test has been developed and tested concurrently with analytical support studies of test procedures and variables. Equipment modifications were periodically accomplished to:

1) Improve its adaptability for testing at depth and in all types of materials

2) Improve the clarity, accuracy and resolution of the measurements

3) Simplify field and of fice data collection and reduction procedures

The following paragraphs discuss and illustrate the details and capabilities of this equipment. The intent of this section is to provide a full understanding of the working mechanisms of the equipment such that similar equipment could be readily fabricated. Details regarding the use and maintenance of this equipment are presented in Sections 5 and 6.

\subsection{ANCHOR AND HAMMER ASSEMBLY}

Shear energy is transmitted to the soil by striking an anchor system which is expanded tightly against the walls of the borehole. Two anchor systems have been developed. One anchor is a heavy hydraulic system designed to operate in a 9- to 10inch diameter uncased borehole. The other is a pneumatic anchor designed to operate in a 5-inch diameter borehole.

\subsubsection{Hydraulic Anchor System}

Details of the hydraulic anchor system are shown in Figure 4.1. This anchor is 4 feet long, weighs about 200 pounds, and expands from 8 to 12 inches in diameter. This assembly contains three aluminum curved plate segments which are expanded in a horizontal direction by nine arms connected to one vertically oriented 25ton double acting hydraulic ram. A hand-operated pump and gage is located at the ground surface to control and maintain the hydraulic pressure in this ram. When expanded, this ram forces the plates outward, pressing them tightly against the walls of 

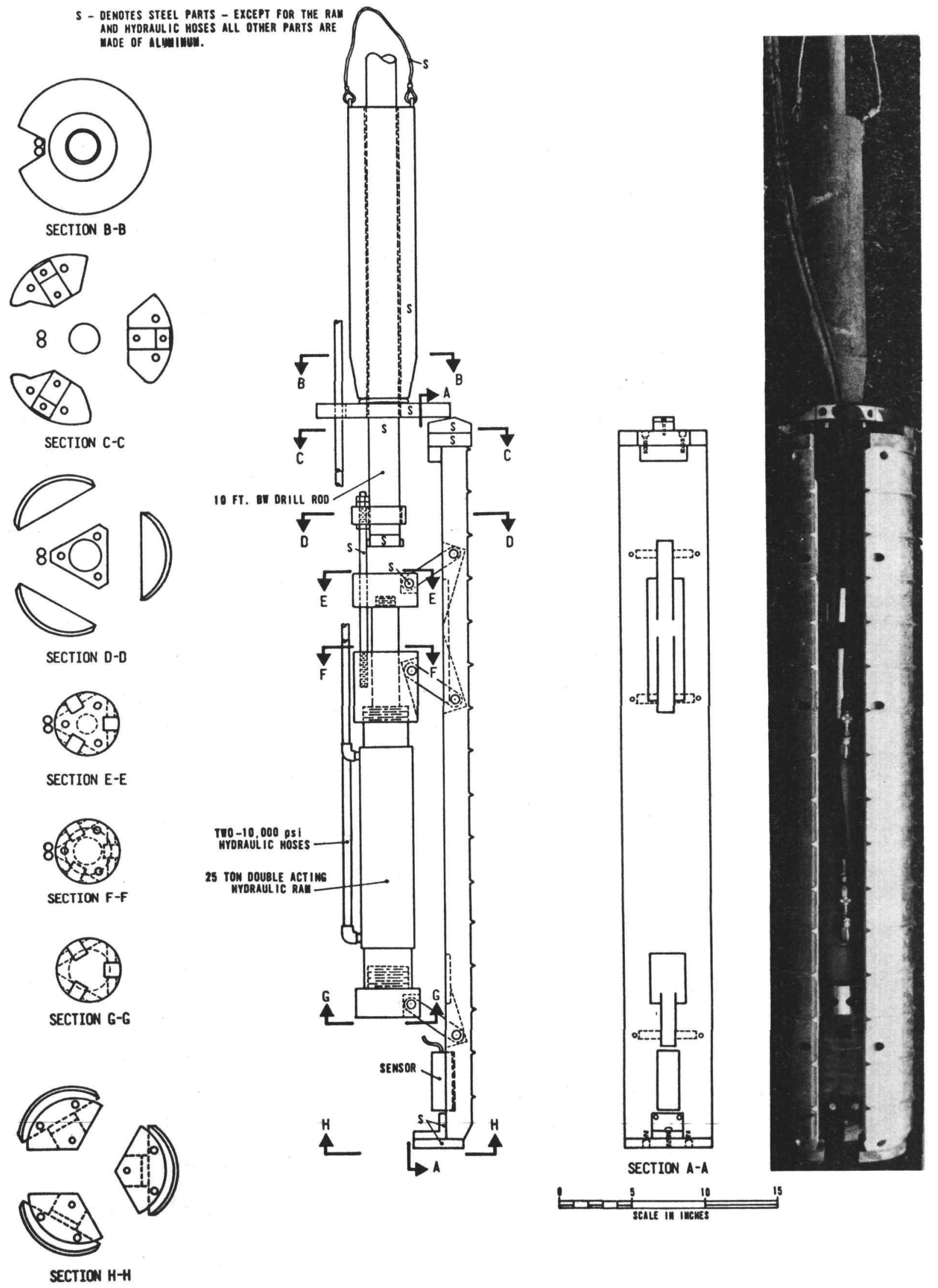

FI'GURE 4.1 HYDRAULIC ANCHOR DETAILS 
the borehole. Small triangular-shaped ribs have been fabricated into the outer face of the anchor plates to provide extra gripping power with the soil. These pointed ribs extend $1 / 4$ inch beyond the smooth curved portion of each plate. In fabricating these plates, three $2 \times 6$-inch by 4-foot long strips of aluminum mounted (tack welded) on triangular templates are turned in a lathe to provide a curvature on each plate of 9 inches in diameter.

Each of the plates is fastened to the ram by three equal length arms. The arms are positioned so that the three plates remain aligned parallel to each other at all times. This further assures that the ram is centered in the hole and that the tops of each plate are at equal elevations.

Vertical sensors have been attached to two of the three plates. This arrangement allows simultaneous measurement and comparison of velocity records. Also, having two sensors on the anchor provides a back-up system should one of the sensors malfunction.

As shown in Figure 4.2, the 1-inch thick, 9-inch diameter circular striking plate, supported by the three plate segments, transmits the impact energy from the falling weight to the anchor. A notch in the side of this circular plate permits the hydraulic hose and electrical cables to bypass the plate and run to the ground surface. Two steel shoes are fixed to the top of each of the three plates immediately below the 9-inch striking plate. The large pie-shaped shoe helps prevent soil from falling into the center of the assembly, serves as a guide for the hydraulic hose and provides an enlarged area for reducing the unit pressure on the plates during impact. It also prevents the striking plate from falling between the three plate segments when the anchor is fully expanded. The smaller shoe or steel block on top of the larger shoe is to distribute a uniform vertical impact loading along the centroid of the plates. Highly eccentric loading on the top of the plate segments would cause them to flex or bend and transmit higher-frequency compression waves into the soil which would distort the wave shapes being measured. 


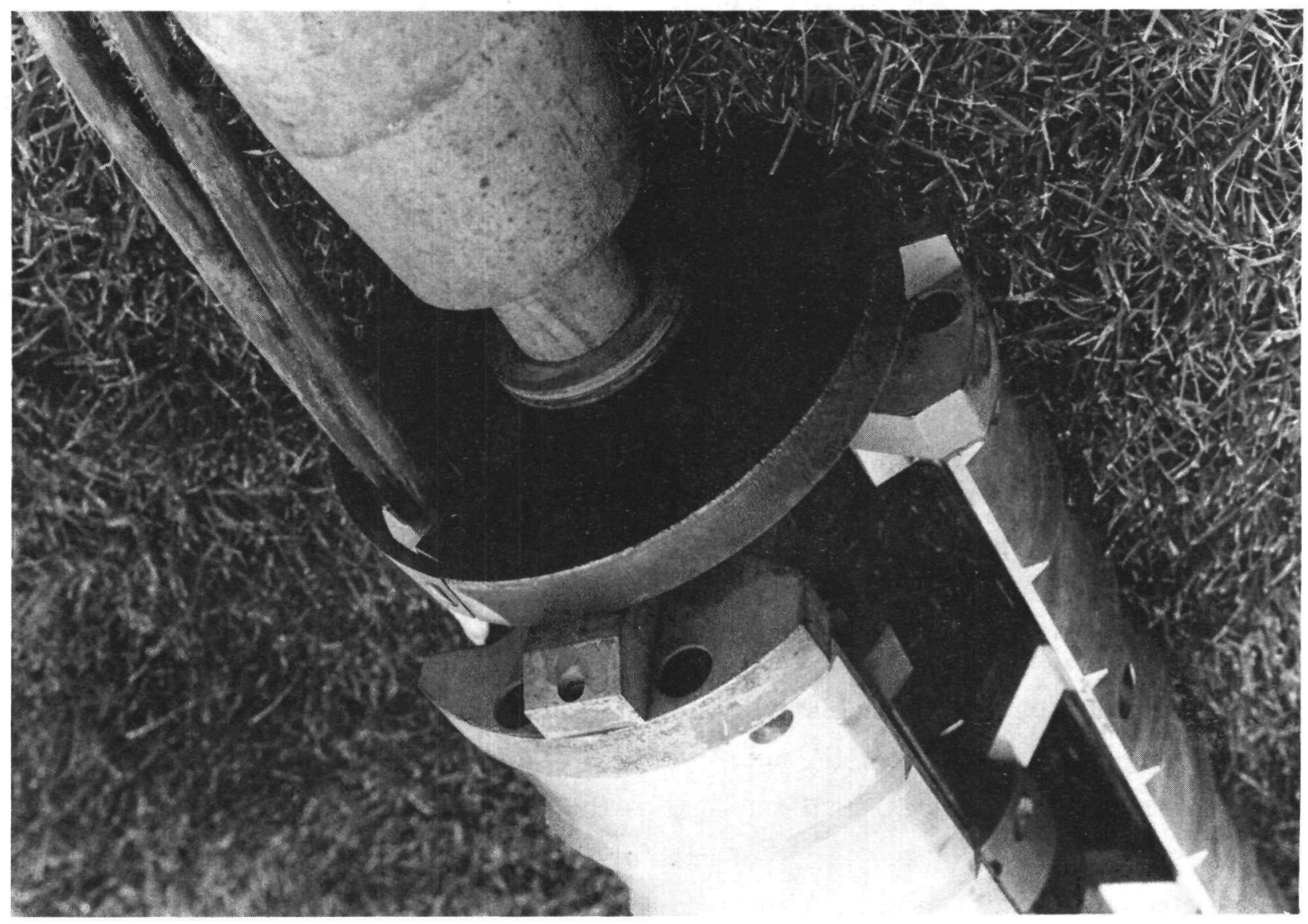

FIGURE 4.2 HAMMER ASSEMBLY (HYDRAULIC ANCHOR) 
On top of the circular striking plate are two Belleville springs stacked in series (Figure 4.2). These springs (with a combined stiffness of about $300,000 \mathrm{lbs} / \mathrm{in}$.) receive and transmit the impact of the hammer to the anchor assembly in a more controlled form. This controlled impact results in clear, repeatable free field velocity time history records (Figure 2.2).

Two different length steel cylindrical sleeves, weighing 58 and 150 pounds, are used as hammers. The sleeves ride over and are guided by the BW drill rod. These weights are controlled from the ground surface by a steel hoisting cable. Usually this cable is attached to the cat rope on the drill rig. The rope in turn passes over a pulley in the top of the drill rig derrick and wraps around the cat head enabling the weights to be easily raised and dropped. The hammers are also light enough that in many cases the drop can be achieved manually without using the cat head. A combination of either of the two hammers and different drop heights provides a wide variation of impact energies to the soil anchor.

The anchor assembly together with the hammer is raised and lowered into a borehole on the end of the drill rod. The rod is attached to the anchor by inserting one end through a rigid yoke inside the core of the anchor and then placing an enlarged coupling on the end of the rod. The yoke itself is attached to the top of the ram by three rods. This slip type connection allows the weight of the drill rods to be isolated from the anchor during testing by suspending the rods from the ground surface. The distance between the bottom of the yoke and the top of the ram is proportional to the diameter of the hole. This slip distance may be determined at the ground surface by measuring the free vertical travel of the drill rod when the anchor is expanded. Thus the horizontal stress on the borehole is computed from relationships plotted in Figure 4.3 of hole diameter and anchor jacking pressure. The maximum hydraulic pressure that can be applied to the ram is 10,000 psi. At this pressure, a maximum radial soil pressure of about 7.5 tsf is possible. 

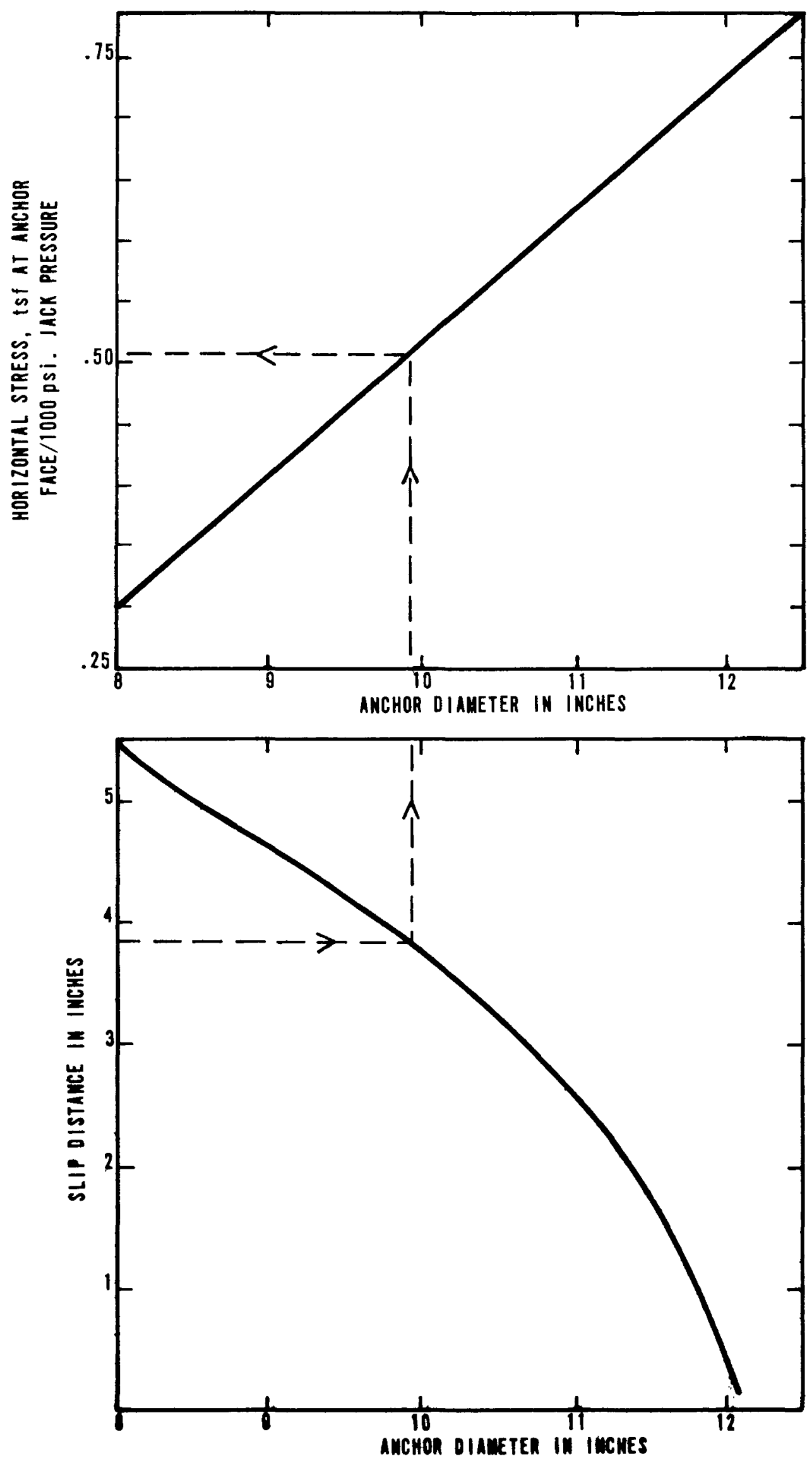

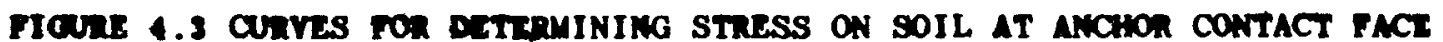


The bottom part of each plate segment contains pie-shaped plates or shoes. In the retracted position, these shoes completely close of the bottom of the anchor, preventing the passage of large-diameter suspended materials. These shoes are especially useful when working with organic materials or when heavy mud is needed to maintain hole stability.

\subsubsection{Pneumatic Anchor System}

The second anchor developed in this program functions much as the first except that this system operates with compressed air or nitrogen and is designed for a 5-inch diameter borehole. This air operated "pneumatic" anchor is 5 feet long, 4.25 inc'les in diameter, weighs about 150 pounds and is formed by three steel plate segments stirrounding an inflatable packer. A 90-pound hammer, similar to those used with the hydraulic anchor, is used to transmit impact energy to the system.

Details of the pneumatic anchor are shown in Figure 4.4. The curved plates are made from 3.5-inch diameter double extra strong pipe cut longitudinally into three segments. The core of this system consists of a high pressure packer unit (burst pressure of $800 \mathrm{psi}$ ). The packer contains a commercially available 2 1/2-inch O.D. steel wire reinforced rubber unit, which expands to a maximum diameter of about 6 inches. Pressure is applied and regulated at the ground surface. Coupling is achieved by expanding this unit outward thus pressing the plate segments tightly against the borehole walls. As the unit expands laterally, the lower end of the packer moves upward with an inner rod as a piston. This prevents the development of longitudinal tensile stresses in the packer.

The anchor assembly is held together by three sets of six short cables. When the anchor is expanded, the middle set of cables attached to thowtower part of the packer becomes loosened causing the plates to hang in the borehole by the other two sets of cables. This hanging action causes the three plates to become vertically aligned. When the air pressure is released the piston action of the packer tightens the system of cables and retracts the curved plates tightly against the inner packer. 

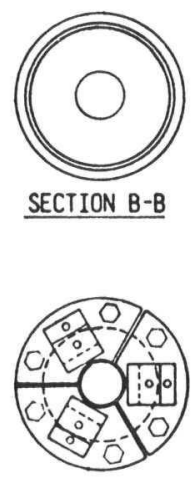

SECTION C-C

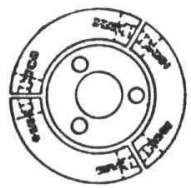

SECTION D-D

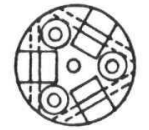

SECTION E-E

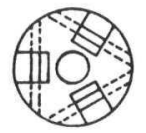

SECTION F-F

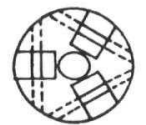

SECTION G-G

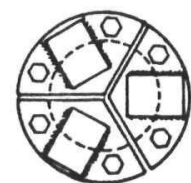

SECTION H-H
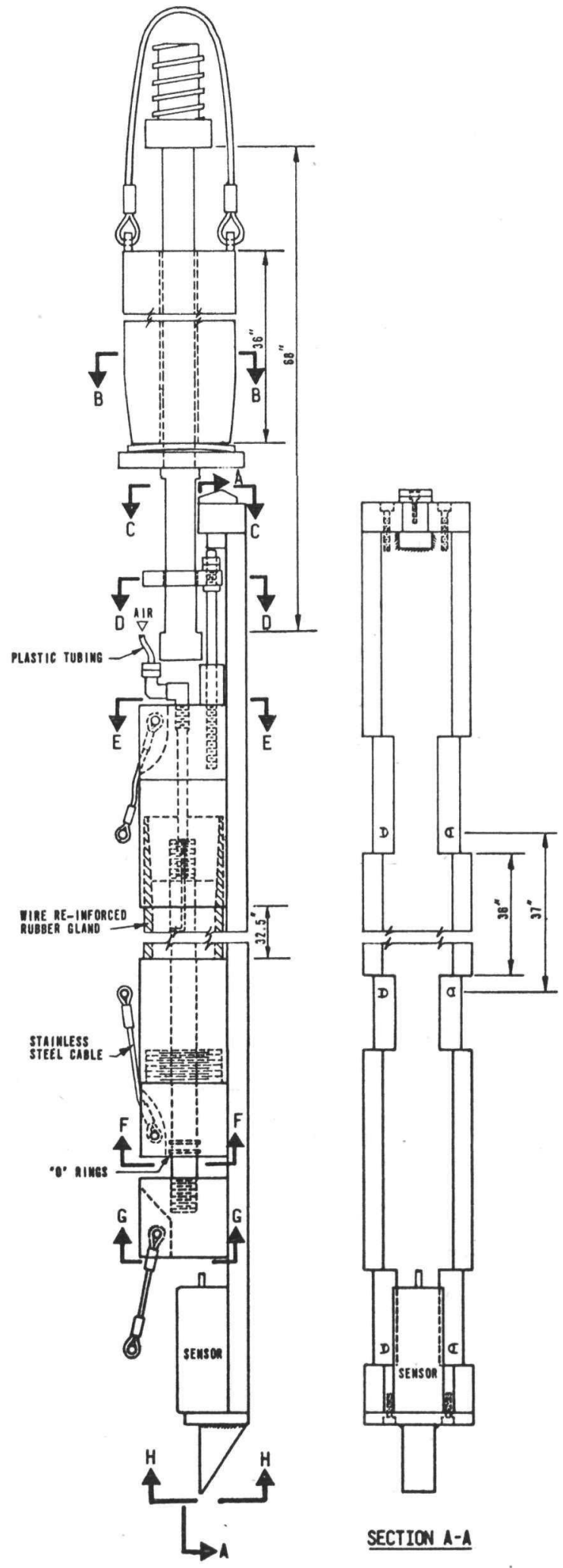

SECTION A-A
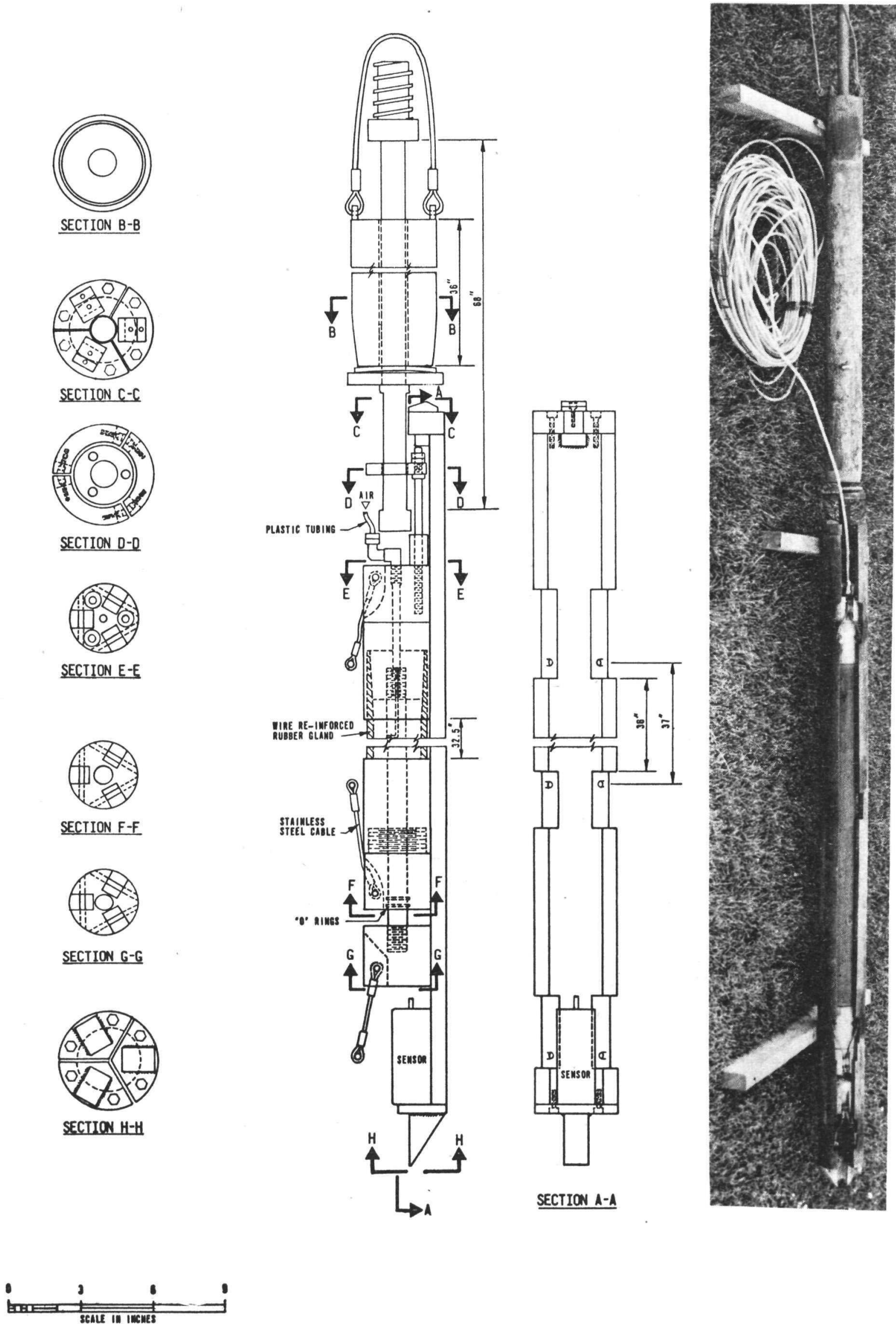

FIGURE $\$$. PNEUMATIC ANCHOR DETAILS 
Energy is transmitted to the pneumatic anchor through a system similar to the hydraulic anchor. A photograph of the striking plate, spring (approximately 160,000 lb./in.), yoke, and upper shoes used with the pneumatic anchor, is presented on Figure 4.5 .

The smaller size and different construction of the pneumatic anchor created design problems that were not encountered with the large anchor assembly. The major problem was to prevent the striking plate from entering the anchor assembly. This could result due to the small diameter of the striking plate. Also, the cable arm suspension system of the anchor plates does not necessarily keep the plates parallel upon expansion and could result in the striking plate entering the assembly. If the striker plate entered the assembly, it could become lodged beneath the shoes of the expanded anchor and prevent its withdrawal from the boring. Also, if the striking plate entered the system, hammer blows could be directly applied to the internal packer system, causing damage and possible loss of the anchor.

To minimize this possibility, a built-up section was added to the guide rod. This section restricts the distance which the striking plate spring and hammer can move downward with respect to the yoke and internal parts. There is a slip distance provided beneath the yoke for the guide rod so that the hammer is truly striking on the three plates rather than the built-up section. With this system, procedures have not been developed for determining the exact hole diameter and radial pressure. However, the radial contact pressure may be estimated from the air pressure required for coupling and the approximate hole diameter.

A pair of shoes is also provided on the base of each of the three plates. These shoes help prevent excess material from reaching the internal parts of the system. More importantly, however, the outer shoes provide a tapered end for guiding the bottom of the anchor over soil ridges, protruding gravel particles, narrow spots or other obstructions that may be encountered in the boring. 


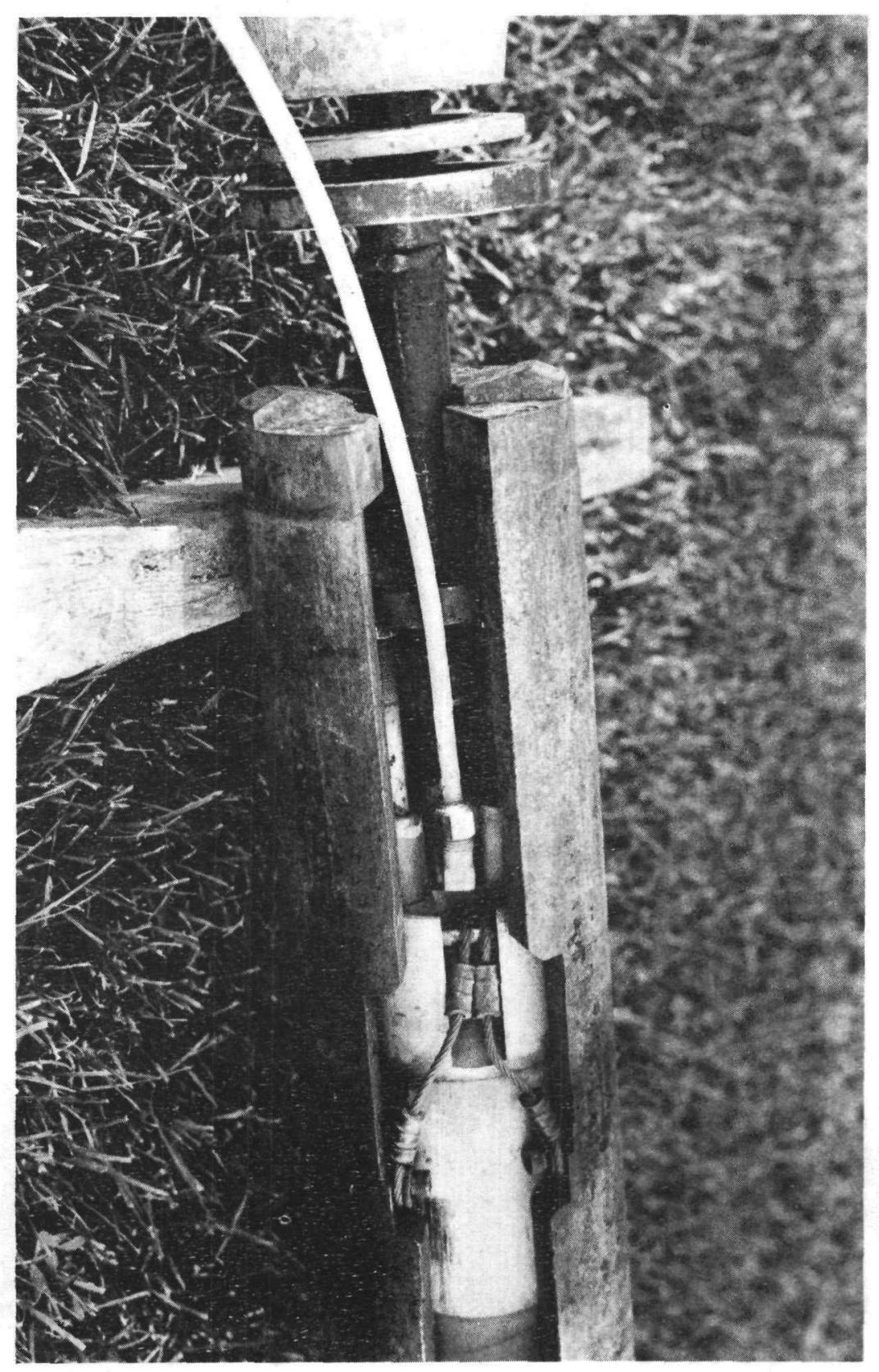

FIGURE 4.5 HAMAER ASSEMBLY (PNEUMATIC ANCHOR) 


\subsection{SENSING EQUIPMENT}

The sensor units for this test consist of two velocity transducers (geophones), one oriented vertically and the other oriented horizontally at each recording station. Because wave shape characteristics are important to data reduction in this test, all transducers used should be the same types (brand and model) and should operate in both vertical and horizontal positions. In previous efforts, all transducers were matched to respond identically with an accuracy of $\stackrel{+}{-1 / 2}$ percent at an average frequency of $200 \mathrm{hz}$. The manufacturers will usually test these transducers on a shake table and certify them for this accuracy.

The velocity sensor package used for free field measurements is illustrated in Figure 4.6. This package consists of two transducers which are mounted in a watertight, aluminum sensor case. The transducers are held in place with a lucite frame and are cast permanently into position within the case with an epoxy resin filler. The steel end post supports, which attach the sensor case to the holder, were designed of fset from the center to permit adjustments in the diameter of the sensor package. As shown in Figure 4.6, the entire unit will easily fit in a 3-inch casing. If the sensing unit is rotated 180 degrees in the holder, it will work in casings or holes of up to 6 inches in diameter.

The holder consists of a 1 1/2-inch diameter, 1/8-inch thick inflatable rubber, cylindrical packer with two short aluminum heads fastened in each end. A steel rod, extending through the packer, connects the aluminum heads and provides rigidity to the system. Coupling the sensors to the wall of the borehole is achieved by pressurizing the rubber packer with compressed air or nitrogen. The rubber packer can be expanded to a maximum diameter of about 6 inches. A small compressed air or nitrogen tank (40 or 80 cubic feet) usually contains sufficient air for inflating the packers for complete testing at one site provided leakage is kept to a minimum. A brass manifold with individual needle control valves can be fabricated from commercially available couplings to pressurize all packers from the single tank. 

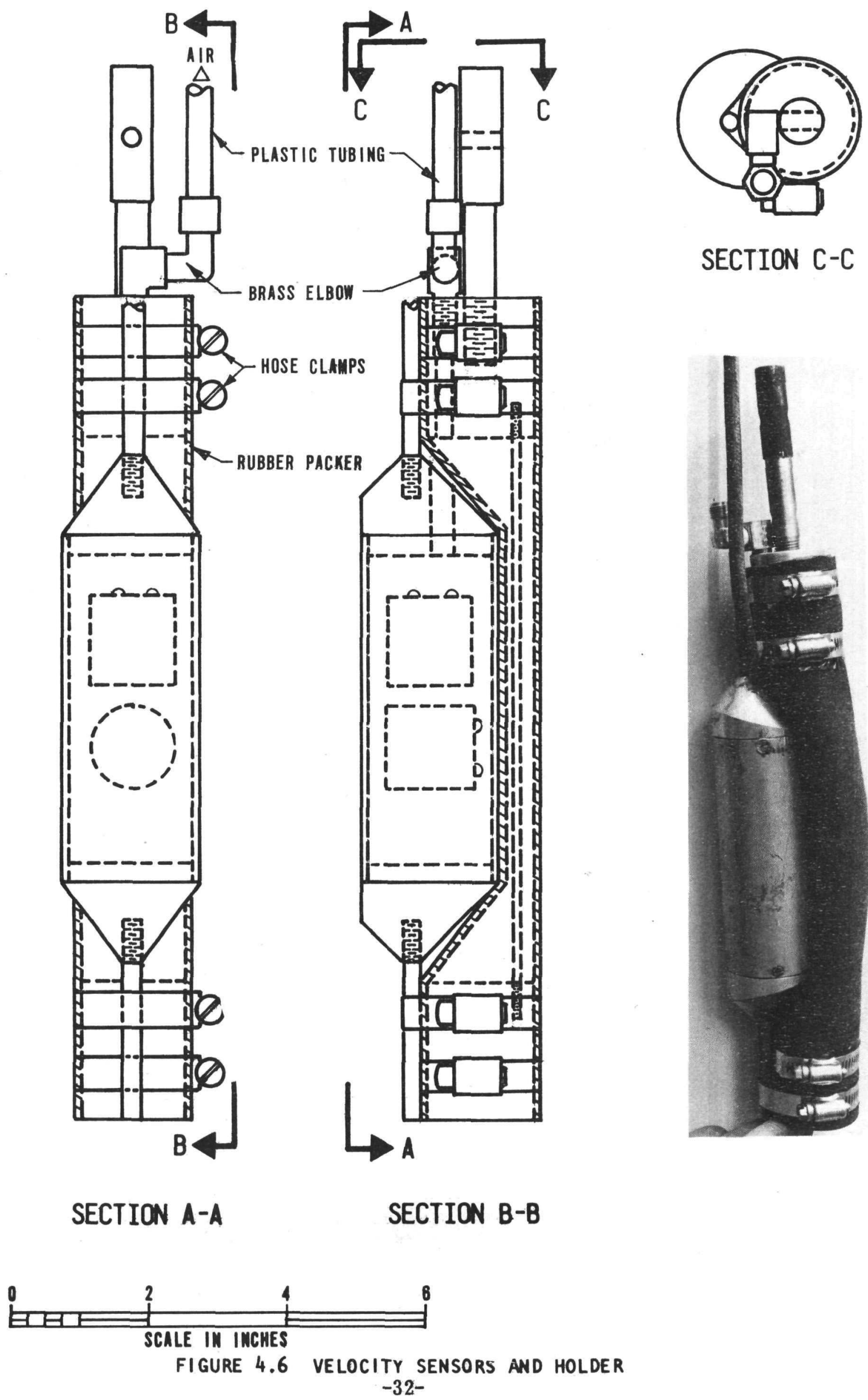
Orientation of the sensors is maintained at the ground surface through 10 -foot long, 1/2-inch diameter interconnecting steel rods (conduit pipe) fixed to the top of the holder. The hollow rods are lightweight and have 4-inch pegs in each end which can be pin connected with other rods using 1/4-inch bolts. All pin holes are drilled parallel to each other for positive alignment of the rods. Use of 10-foot rod sections facilitates determination of the depth of the sensor.

The velocity transducers positioned on the anchor may either be placed in a single watertight case or in two smaller separate cases. The two transducers shown in Figure 4.7 have been waterproofed by coating the sensors and bare electrical wires with an electrical epoxy resin. The transducers are coated in three stages. First, a mold is placed around the top half of the transducer and filled with a hard resin. After hardening, the system is coated or dipped several times to cover the rest of each transducer. Finally the connection between the rigid epoxy and the more flexible cable is sealed with a more flexible coating compound used for splicing cables. Prepared in this way, the sensors are small enough to fit in the pneumatic anchor where space is greatly limited.

\subsection{RECORDING EQUIPMENT}

The recording console used in the field to acquire velocity time histories from each sensor is shown in Figure 4.8. This console contains four basic units. The waveform recorder located in the lower left corner of the console is the primary central data acquisition unit. This unit is capable of the simultaneous recording and storing of velocity time histories from four independent sources. The stored data from each of the four channels can be extracted from the recorder in either analog or digital form.

The second unit of the console is a single-channel non-storage oscilloscope. This is situated in the lower right portion of the console shown in Figure 4.8. The oscilloscope is capable of simultaneously and continuously displaying in analog form the four signals stored in the wave-form recorder. A typical four-channel display, as seen 


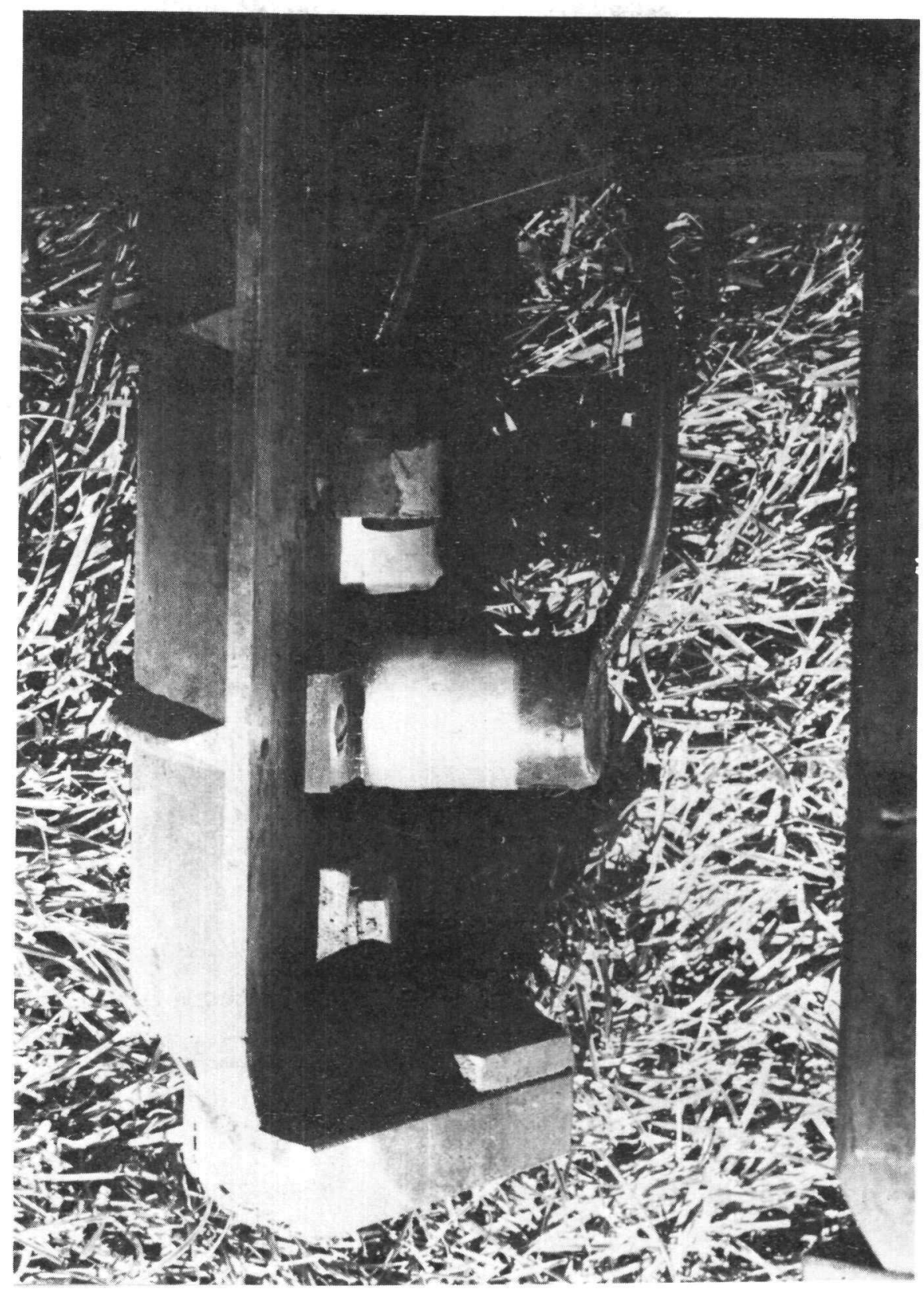

FICURE 4.1 ANCHOR VELOCITY SENSORS 


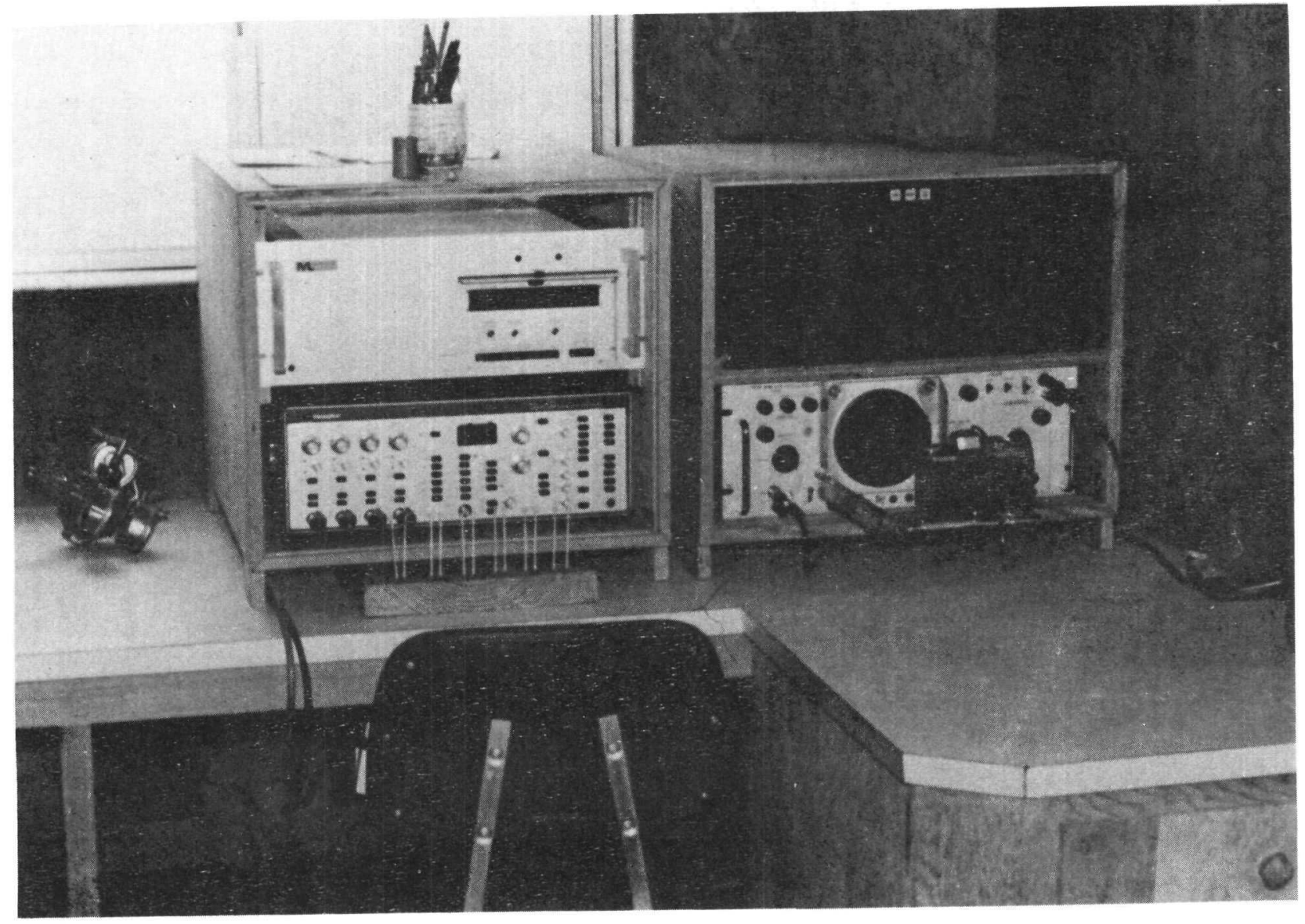

FIGURE 4.8 RECONDINO CONSOLS 
on the oscilloscope screen, is presented in Figure 2.2. Because the information displayed on the oscilloscope is being taken from a memory bank and is controlled entirely by the wave-form recorder, adjustments in time and amplitude of the signals are possible after the event. This feature enables small or critical data parts on any channel to be viewed separately in detail or compared with critical parts on other channels. The oscilloscope is equipped with a camera mounted in front of the screen. Photographs taken of the display provide a back-up recording system and valuable additional graphical records. These photographs may be reviewed during data-reduction operations to determine which tests are best suited for further study and processing.

Other analog systems or equipment not shown are also available for storing or displaying the records. These include strip chart recorders, $x-y$ plotters or multichannel FM tape recorders. In general, chart recorders and plotters are much slower at producing results for field assessment and do not enable successive channels to be easily compared in the field. FM tape recorders provide a means of storing the data, but do not provide a display of the data in the field unless it is played back through the oscilloscope. Also for this playback capability, the oscilloscope must have multichannel and storage features. For a permanent record, directly obtained digital data provides better resolution in time and amplitude than the analog data. Furthermore, analog to digital (A/D) conversion is not a trivial matter, and care should be exercised when working with such data and data-acquisition systems.

The third unit of the console is a magnetic digital tape recorder. This unit occupies the top right portion of the console shown in Figure 4.8. Data from all four channels of the wave-form recorder is transferred to this unit where it is placed directly on computer compatible digital magnetic tape. By placing the data on tape, field data-collection time is greatly reduced and also rapid data reduction can be carried out using time-saving computers. Records for each test can be digitally placed on the tape in less than 30 seconds. Each of the four channels is printed in sequence as 1,024 words or 4,096 words in total. In most tests each digital word is printed with a time and amplitude resolution of 0.05 or 0.02 milliseconds and one part in 1024, respectively. The recording time of this unit is adjustable, ranging between 0.01 milliseconds and 10 seconds per word. 
The wave-form recorder also has an adjustable pretrigger switch which enables the recording of data preceding the trigger point. This unique feature ensures recording of all pertinent parts including the initial rise of a signal. This is accomplished by having the unit record continuously until the trigger point is reached. Then an adjustable delayed trigger is used to stop the recording process and freeze in memory the data which was received in the period preceding the delayed trigger. The pretriggering feature combined with an adjustable recording time allows recording of the event for maximum resolution in both time and amplitude.

The fourth unit of the console is the interface unit. This unit is located in the upper left portion of the console shown in Figure 4.8. The interface unit provides the necessary electrical circuitry for transferring the digital data from the wave-form recorder to the digital tape recorder. Also, the interface unit contains manual controls and automatic options which enable test data and labels with both time and amplitude scales for each of the four channels to be organized systematically on the magnetic tape. This greatly simplifies data reduction since little additional information is required on the tapes for computer processing. One disadvantage of this system is that there is no way to verify the recorded tapes in the field. Read options are available to this tape system, but they add significantly to the system cost.

Three other components are commercially available and could be used to store the digital data for later processing. These include high speed digital printers, teletype systems or digital plotters. The printers produce results on standard adding machine paper at 20 lines per second and six lines per inch. At this rate and spacing, more than three minutes would be required per test to print the digital results on some 57 feet of paper. This alternative is impractical due to the quantity of paper that is generated. Teletype machines are equally as impractical as they are even slower than the printers. Furthermore, since the data will be processed by a computer, it is unreasonable to record it in any manner which cannot be directly interfaced with a computer. 
One advantage of a digital plotter over the above systems would be that hard copies would be produced directly in the field assuring quality data to the resolution needed. Unfortunately, digital plotters are very bulky, extremely costly and generally not applicable for field use. Therefore, to obtain plotted digital data would probably require a magnetic tape unit to record the data in the field. The data tape would then be placed on another component and the data transmitted over telephone lines to a plotter for the hard copy record. This approach, in our opinion, does not appear favorable for practical application.

\subsection{SURVEYING EQUIPMENT}

The inclination of each borehole is determined with a commercially available inclinometer. There are five basic categories of inclinometers in use. These categories are distinguished by the type of sensor selected to measure the inclination of the probe relative to gravity. The four main types of sensors are:

1) Pendulum-activated Wheatstone bridge circuit,

2) Strain gage type,

3) Accelerometer type,

4) Photographic type,

5) Gyroscopic type.

The first three types measure the inclination of the casing in two mutually perpendicular near-vertical planes while the last two require no orientation within the casing or borehole. Generally, the accuracy of the fourth type is lower than the others and the fifth type requires purchase of the equipment or hiring of the personnel to make the needed measurements. The first three types are commercially available for purchase or rental and may be used more easily. Of these instruments the accelerometer type, with a reported sensitivity of 1 in 10,000, was used in these studies. This device is shown in Figure 4.9. 


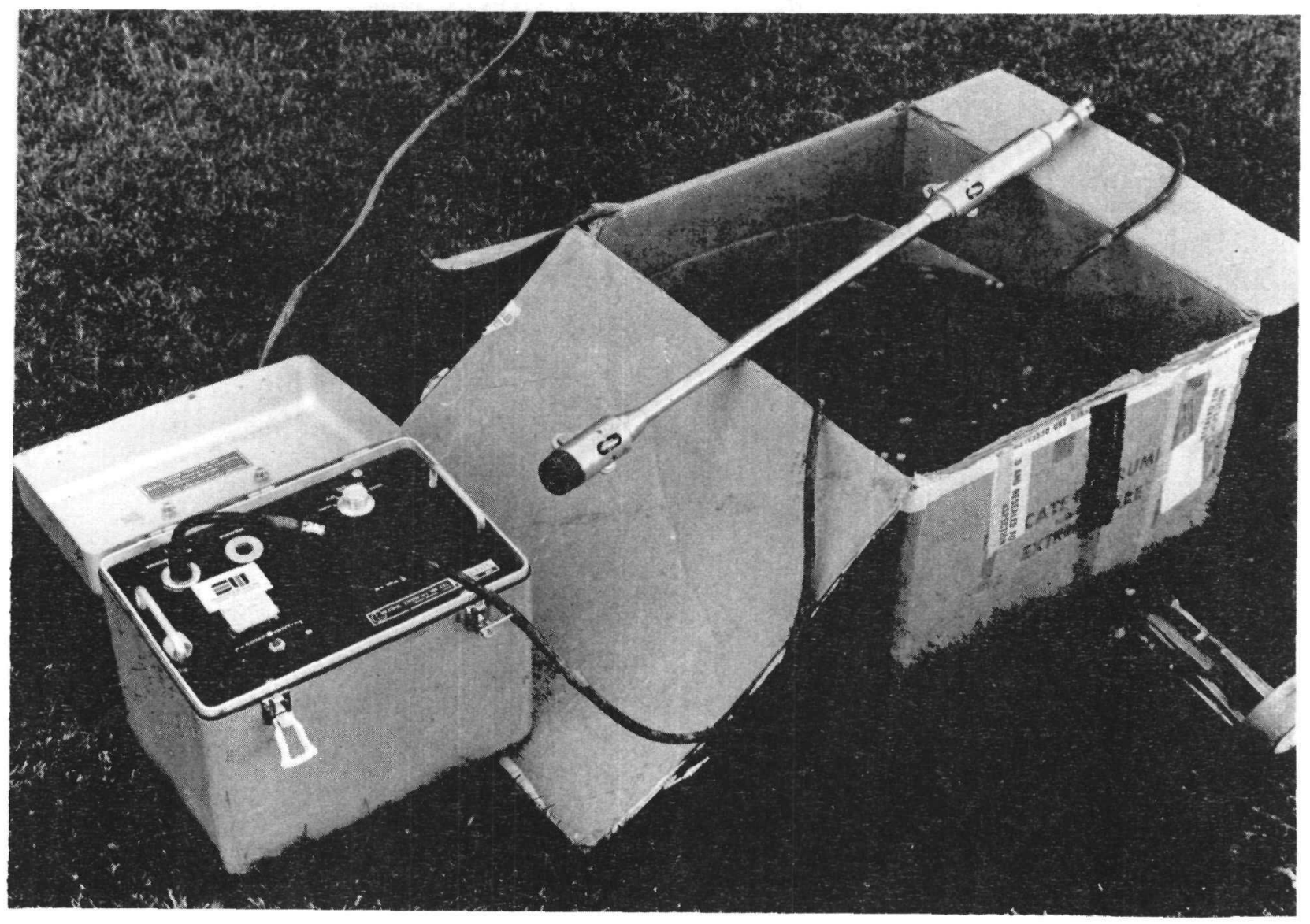

PIGURE 4. IMCLINOETER 
The 2-foot long probe is lowered into a casing which is either temporarily or permanently installed in each boring. Spring loaded guide wheels on the instrument track in special continuous vertical slots grooved in the casing. These slots control alignment and orientation of the instrument. The two sensors within the inclinometer record the inclination on perpendicular planes at 2-foot intervals for the entire depth of the boring. These inclination measurements are then summed to establish the horizontal displacement of the borehole at any depth relative to the top of the borehole. By measuring the surface distances between holes, the distance between respective holes at any depth can be computed. The measurements at the surface are made relative to the edge of the borehole closest to the anchor, since this is where the sensor will be positioned during the test. Measurements for the anchor hole are made relative to the centerline. Typical results of three surveys are presented in Figure 3.1. 


\section{FIELD CONSIDERATIONS AND PROCEDURES}

In situ impulse testing has been conducted at eleven sites. Through this field testing, valuable experience has been gained in drilling, surveying, and testing procedures. While the general procedures outlined in Section 2 appear straightforward, advance planning is essential. This will minimize confusion and costly delays in the field.

The following paragraphs describe the practical considerations of planning and coordinating an adequate testing program at a proposed site. Also discussed are details of field drilling, surveying and testing procedures.

\subsection{DRILLING CONSIDERATIONS}

The test equipment described in Section 4 has been designed to work with conventional soil sampling drilling rigs. The most commonly used soil boring techniques are rotary and auger drilling methods (SW-AJA, 1972). The main advantage of both of these methods is the ability to advance rapidly through most soil types without causing excessive disturbance of the surrounding medium.

Choice between these two drilling methods is largely controlled by the availability of equipment. Solid stem augers are typically used in areas underlain by cohesive soils, since these materials generally will not cave during drilling and sampling operations. Otherwise, either continuous flight hollow stem augers or rotary drilling equipment are used. Both of the latter types of equipment can penetrate most soils and many soft rocks. The average 8 to 10 -inch diameter hole produced by the hollow stem auger is well suited for the larger hydraulic anchor equipment. Fine adjustments in the hole diameter can be achieved by changing the size of the cutting bit on the end of the auger. This auger, however, is not suitable for drilling the sensor holes since it produces too large a hole. Fortunately, most augering rigs can adapt to the smaller solid flight augers or even convert to rotary methods. This increased flexibility in augering equipment is sometimes needed when advancing through soil and soft rock into hard rock. 
Rotary equipment is also suitable for drilling both the sensor and anchor holes. The hole size can be easily varied by changing the size of the drill bit. Rotary drill bits, in both tricone and drag bit configurations, are commercially available in many sizes.

Borings advanced for the free field sensors should be between 3 and 6 inches in diameter. Holes with small diameters are preferred since they are generally more stable and disturbance is minimized. Actual size of the boring will depend upon the maximum size of the permanent or temporary inclinometer casing that will be used to survey the boring. Uncased holes, which will be cased temporarily during the hole survey, should be drilled 1 inch larger than the inclinometer casing. Holes that will be permanently cased should be drilled about 1 1/2 inches larger than the permanent casing. This is to allow ample room for both the permanent casing and a 1-inch O.D. grout pipe in the hole. In instances where inclinometer casing is not used in the permanent installation, the permanent casing has to be sized to allow passage of a temporary inclinometer casing for use in surveying the hole.

Drilling slightly oversized sensor holes is sometimes advised especially when caving soils are encountered and permanent casing is needed. The extra tolerance is usually sufficient to overcome any small amounts of squeezing or crookedness in the holes that may restrict passage of the test equipment or casing.

Soil permeability is another factor in addition to hole stability that may require the use of casing in the sensor holes. Closely spaced holes drilled by rotary techniques in clean sands and gravels may become hydraulically interconnected in the drilling process. This may result in soil cuttings from one hole flowing to an adjacent hole and filling it. Development of interconnection requires that the remaining portion of the intact hole be cased. In gravelly soils, casing is nearly always needed. High pump pressures (100 to $200 \mathrm{psi}$ ) needed to remove the gravel cuttings greatly increase the chances of hydraulic interconnection. As each hole is drilled, more fines are washed out of the gravel matrix, thereby increasing the permeability of the surrounding mass and the probability of hydraulic interconnection. 
The hydraulic and pneumatic anchors work best in holes with diameters of about 10 and 5 inches, respectively. The selection of the bit or auger size and the anchor for a given site is largely a function of the soils or rock being penetrated. The large hydraulic anchor is more suited for use in soft rock and all soils expect gravels. The small pneumatic anchor works in gravels and in the more competent soils and rock.

Experience in testing soft soil sites has been that a 9.5-inch diameter drill bit will produce a satisfactory 10-inch hole for use of the hydraulic anchor. Compared with more competent soils, the drilling operation produces a larger hole size and zone of disturbance in the softer materials. This is due to the natural tendency of these materials to soften, deteriorate, squeeze or slough when disturbed. However, these soils are compressed by the anchor when it is expanded, which effectively reduces the zone of disturbance. There is generally a smaller zone of disturbance in more competent materials such as stiff or hard clay or silts and dense sands or soft rock. In these materials, a $97 / 8$-inch or 10-inch diameter bit has been found to produce a satisfactory 10-inch hole. Since it is difficult to advance and/or maintain a largediameter hole in gravels and hard rock, it is generally preferred to drill a 5-inch hole and use the pneumatic anchor.

Selection of a drill bit size for a 5-inch anchor hole also depends on the soils and the general guidelines above. A 4 7/8-inch diameter bit has been used with good results in the firmer or more compact soils. It is recommended that a slightly larger drill bit size be used in hard rock and gravel to account for irregularities in the hole which would tend to bind the anchor. Selection of a bit size for drilling gravels is largely a function of the density of the material, its stability, and the experience of the driller. Experimenting in drilling the sensor holes will aid in selecting a drill bit size for the anchor hole.

Maintaining hole verticality and alignment greatly improves the quality of the data and the effective depth of testing. This requires care in aligning and leveling of the drill rig. Additionally, the use of heavy drill collars (at least 10 or 20 feet long) and large or stiff rods (NX) or auger with rigid (tight) connections help to improve the alignment and verticality of the boreholes. 
Additional drilling factors include the experience of the driller in operating the equipment. Factors including feed and control of pump pressures, pump volumes, drilling speed, and down pressure all affect the condition of the borehole sidewalls and their stability. Therefore, a successful drilling and testing program is dependent on a familiarity with the driller, the drilling equipment and their combined capabilities.

A final consideration is an evaluation of the need for using the drilling equipment during the testing phase of the work. Experience has shown that use of the drill rig is essential when testing to depths greater than about 20 feet. This equipment is used in the following ways:

1) Raising and lowering the anchor equipment in the borehole. This is especially time saving if part of the equipment becomes damaged while testing at depth and has to be removed to be repaired.

2) Dislodging the anchor from the borehole when it becomes embedded or tightly stuck to the soil walls after completing a test. This sometimes requires several thousand pounds of pull or push.

3) Pushing the anchor through narrow zones or restrictions in the boring.

4) Preconditioning the large anchor hole prior to the start of daily testing by circulating fluid to remove cuttings that may have settled. This is primarily applicable when using rotary equipment.

5) Operating the hammer.

6) Removing soil particles that have collected around the hammer, spring, and the internal parts of the anchor by circulating drilling fluid through the rods.

7) Flushing or breaking bridges that may develop within the sensor holes. This is accomplished by jetting water through a plastic hose attached to the rods used to raise and lower the sensors.

8) Fishing for equipment that becomes lost in the hole. 


\subsection{TESTING CONSIDERATIONS}

The primary test consideration is selection of the appropriate anchor system and hammer. The larger hydraulic anchor usually works best in the upper 100 feet of most soils. It results in clearer records and more complete information at the anchor and is generally more durable than the pneumatic anchor. For these reasons, this larger anchor system is more suited for the majority of routine soil tests.

The smaller pneumatic anchor is more suitable for testing at depths greater than 100 feet. This system is also used where there is a question of hole stability with the large anchor and has provided satisfactory test results in rock. It is advantageous to use the small anchor to test hard rock in that the drilling and reaming time is greatly reduced.

Where a combination of the above conditions is encountered at a site (i.e., soil underlain by rock), both anchors have been used. The small anchor is used first to accomplish all testing, at depth. Then the hole is reamed at shallower depths to accommodate the larger hydraulic anchor. Testing must follow this sequence since it is extremely difficult to lower the pneumatic anchor through the large 10-inch hole into the smaller 5-inch hole.

Gravels are difficult and costly to drill and test. The large particle size and high permeability of this material causes drilling difficulties and often results in caving. The completed hole generally has poor alignment and irregularities due to local cavities and protruding zones. Permanent casing is nearly always used for the sensor holes to eliminate caving and damage to the in-hole equipment.

Tests have not yet been conducted using anchors inside cased holes. Therefore, with caving conditions in uncased holes, there is a constant risk of losing expensive inhole equipment. This is especially true where working with gravelly soils. During testing, gravel particles may fall into the anchor system and prevent its removal. This 
risk may be minimized by operating the anchor below the bottom of flush walled steel casing. This is accomplished by setting the casing about 3 feet above the planned test depth. The anchor is then lowered through the casing and coupled to the boring wall, with the hammer positioned just inside the casing. The test is conducted in the normal manner and then the anchor is retracted into the casing. The anchor is then expanded within the casing and the entire assembly is lowered to the next depth where the testing process is repeated. This test operation is slow but usually so are all other operations when drilling and testing gravels.

When using this technique, the hole size should not be made significantly larger than the outside diameter of the casing. Otherwise, it may be difficult to couple the anchor to the bore-hole walls. Additionally, use of a small-diameter hammer is recommended to minimize the possibility of the hammer binding or rubbing on the casing.

A similar technique can also be used to test soils below a marginally stable gravel layer. First, the hole is cased to just below the gravel layer. Then the lower portion of the hole is tested in a normal manner with the pneumatic anchor. Next, the gravelly portion of the hole is tested as described above. Finally, the upper portion of the hole is reamed to a 10-inch diameter and tested with the hydraulic anchor.

Selection of the hammer weight largely depends upon the stiffness of the material and the thickness of the drilling fluid. The smaller 58-pound hammer is used for soft to medium stiff materials or when jacking pressure (hydraulic) does not exceed about 3,500 to 4,000 psi. This generally results in negligible slippage of the anchor and clear-signal records. On the other hand, excessively heavy drilling fluid will hinder the operation of the small hammer and will result in inconsistent records. These effects are offset by using a heavier hammer and a higher jacking pressure on the anchor. The heavy hammer is more suited for testing stiff soil and rock. In most cases, a drop of the heavier hammer in excess of 2 feet has caused excessive slippage of the anchor. 


\subsection{FIELD DRILLING AND CASING INSTALLATION PROCEDURES}

In general, the in situ testing program is conducted with four borings. These holes are typically advanced to depths of 100 to 200 feet in soil or to a lesser depth if rock is encountered. The borings are aligned in a straight line as shown in Figure 2.1. The three sensor borings are about 4.5 inches in diameter and are spaced at 4, 8, and 16 feet from the fourth anchor boring. The anchor boring is either about 5 or 10 inches in diameter.

The first hole drilled is the sensor boring located closest to the proposed anchor hole. Soil samples are periodically taken from this boring as the drilling progresses. This provides information to assess material types and the drilling techniques and procedures that will be used for the remaining borings. If caving does not appear to be a potential problem and conditions look favorable, then the remaining sensor holes are drilled. The anchor hole is usually advanced last, because the rig must be set over this hole to operate the heavier test equipment. This procedure not only avoids extra moving of the rig but also minimizes the time which the walls of the uncased larger anchor hole are exposed prior to testing.

The testing pattern should be changed if excessive drift develops in the initial hole. This generally results in assigning the initial hole a position furthest from the anchor boring (16 feet from the anchor hole). Excessive drift in the alignment of the more closely spaced holes can result in holes converging to a common distance from the anchor. This, in effect, causes two potential data stations to act as one and may require extra holes to be drilled. The more distant boring is not as sensitive to alignment. A shift of this boring of several feet in any direction does not seriously affect the value of the station in terms of arrival times, when compared with the more closely spaced stations. Hole alignment is determined by surveying techniques described in the next section. This survey is normally performed immediately following the completion of each hole. 
Local caving of the walls in the initial hole also may result in a change in the hole-drilling sequence. This usually requires that permanent casing be installed in all sensor holes. After casing the first sensor hole (4 feet from the anchor boring), the next one drilled is the one located furthest from the anchor (16 feet from the anchor hole). This hole is cased and then the final sensor hole (8 feet from the anchor boring) is drilled. This drilling sequence allows optimum grout set-up times in the adjacent borings and minimizes the risk of hydraulically connecting an adjacent hole and removing its grout.

Use of permanent casing for maintaining hole stability requires special installation procedures to minimize the influence of the grout and casing upon the recorded signal. Test results performed on various types of casings (SW-AA, 1975a) indicated that 3-inch plastic casing was probably the most practical for use with this test and influenced the results the least. This casing may be constructed in 10 - or 20 -foot sections using conventional couplings. Once the casing has been lowered in the hole, it should be permanently coupled with the borehole walls with grout. This grout is normally injected into the bottom of the hole through a coil plastic grout pipe, usually $3 / 4$ to 1 inch in diameter. This pipe is attached to the outside of the lower 20 feet of permanent casing. The grout pipe should not be fixed to the permanent casing at other points, as high pressures could cause the small pipe to elongate, pulling the plastic casing apart at the joints.

In this installation, the casing should be positioned in the hole to the side closest to the anchor boring. This is accomplished by lowering the grout pipe on the side of the borehole away from the anchor hole, forcing the permanent casing to within about $1 / 2$ inch or less from the borehole wall on the side of interest. Voids within the grout are also eliminated with the pumping of grout from the bottom of the hole.

The grout is usually mixed in a large barrel and then slowly pumped through the grout pipe where it exits at the bottom of the hole. The relatively heavy grout displaces any drilling fluids or water that may be in the hole. The operation is 
completed when grout reaches the surface. Some settling of the grout may occur overnight in the upper 5 to 10 feet. This void space can usually be filled the next day with grout dumped from the ground surface. In most cases no attempt is made to salvage the grout pipe.

The grout consists of a mixture of three parts hydrated lime, two parts cement by weight, and enough water to obtain a relatively thick fluid. Minute quantities (about 2 tablespoons) of aluminium powder are added to each 55-gallon mixture to minimize grout shrinkage.

Thin-walled permanent casing, such as sewer, or drain pipe, has been used successfully but can collapse due to excessive local grout pressures that may exist near the tip of the grout pipe. This problem can be eliminated by using a 10-foot section of stiffer plastic pipe for the bottom section of the permanent casing.

Schedule 40, plastic pipe or a thicker pipe is recommended for use in holes which are largely in gravel. Protrusions and irregularities in these holes require that the pipe be relatively ductile and capable of withstanding some abuse during installation. Thin wall casing is usually more brittle and will crack under local pressures. These cracks may allow grout to enter the permanent casing. Also, when drilling adjacent closely spaced holes using rotary methods, the high water pressures (100-200 psi) needed to remove the gravel cuttings can hydraulically reach and cave adjacent thin wall casing.

\subsection{SURVEYING PROCEDURES}

All of the borings must be surveyed to establish accurate travel distances between the holes. The survey is accomplished by inserting a special inclinometer casing with vertical slots into each uncased borehole after it is completed. This casing extends the full depth of the boring and is rigidly fixed at the ground surface. The inclinometer probe is next lowered inside this slotted casing to the bottom. It is then raised systematically with measurements of casing inclination being taken at 2-foot 
intervals along perpendicular planes. After completing one set of readings along biaxial planes, the instrument is removed from the hole, rotated 180 degrees, and again lowered down the casing and the process of measurement is repeated. This second set of measurements provides an extra set of data for checking with the first set. Errors in recordings can easily be detected and corrected in the field. The special temporary casing is removed shortly after these measurements are completed and reused in the other holes. This technique is also used to survey sensor holes in which permanent casing has already been installed.

Relative distances between the borings at depth are obtained by measuring the surface distance between holes and appropriately adding the computed hole inclinations. Since the free field sensors are positioned on the side of the hole closest to the anchor, the reference surface measuring point is the edge of the hole closest to the anchor hole. Distance measurements at the anchor are made relative to the center of the hole (the center of the drill rod).

Survey of an anchor hole drilled with a continuous-flight, hollow-stem auger may be made by placing the temporary casing inside the stem of the auger. The inclination measurements can then be taken and the casing removed prior to pulling the auger. The time involved in surveying a hole, including the lowering and removing of casing, usually takes about 1 to 3 hours.

Survey of a large-diameter anchor hole drilled by rotary techniques requires the following steps. First, a 4- to 5-inch diameter pilot hole is advanced. Next, the hole is surveyed as if it were a sensor hole. The pilot hole is then reamed to the larger diameter. Drift of the larger-diameter hole may be minimized by using the pilot bit to guide the reaming tool. The pilot bit should lead the reaming tool by at least 5 feet. 
A potential source of error in the survey measurement is variation in alignment or spiraling of the grooves in the inclinometer casing. Variations in the groove alignment may result from stress relief in the casing caused by the manufacturing operation. Also, alignment variations may develop when assembling and installing casing in the field. The net effect of these factors may produce a small amount of rotation or spiraling of the continuous grooves. Determination of the amount of rotation is essential to an accurate inclinometer survey, especially where hole drift is significant.

A direct procedure for checking spiral consists of pre-assembling the casing on the ground in 40-foot sections. The rotation of the slots of each section is then measured directly. The 40-foot sections are next put together for the entire length and the total rotation of the slots is summed. Twist may be applied and released to one end of the casing and the rotation rechecked to establish the likely accuracy of the rotation measurements.

The inclinometer casing sections are joined with plastic couplings. The couplings are fastened to the pipe with four 1/8-inch pop rivets at each connection. After the casing is assembled and the grooves aligned, additional holes are drilled in the couplings and each of the sections is labeled. These marks and spare holes will enable the sections to be fastened and unfastened numerous times without having to realign the slots each time with an aligning tool. The sections are unfastened by drilling out the pop rivets with a hand drill. These used pop-rivet holes are never reused. Refastening is accomplished by aligning the labeled sections and new pop-rivet holes and inserting pop rivets in the spare holes. Casing installation and removal is expedited by working with 20-foot sections of pre-assembled pipe. Lubrication of pipe ends with oil also makes the fastening and unfastening process easier.

Using temporary casing in a hole with drilling mud requires cleaning the inside of the casing after each survey. Otherwise, a mud coating will build up on the grooves and prevent proper tracking of the inclinometer. A stiff brush attached to one of the rods used for lowering the sensors will normally remove the mud from the grooves in one quick washing. 


\subsection{IN SITU TEST PROCEDURES}

Most of the test equipment including the casing is transported to a test site in a small trailer. This trailer then serves as a data-acquisition center during the drilling and testing operation. The test equipment is sufficiently portable that it could also be transported to a test site via commercial surface or air carrier. At the site, the test equipment could then be set up in a mobile unit such as a van, truck or trailer.

At the site, the in-hole test equipment is pre-assembled and checked out concurrently with the drilling operation. This includes unloading and assembling all test equipment, checking the recording equipment, calibrating the sensors, and repairing test equipment as needed. Also during the drilling, the inclinometer casing is pre-assembled and checked for alignment. It is then inserted in each boring after it is drilled to survey the hole.

Once all the borings have been completed and surveyed, the test anchor assembly and sensors are lowered into the holes and set at an appropriate test depth. Testing may either start at depth and work to the surface or progress downward from the . surface. Starting at depth and working to the surface tends to minimize the amount of soil material which collects around the anchor assembly. Material collected on or around the anchor tends to become dislodged as the anchor is raised to new test locations. Another advantage of testing deeper first is that fine drill cuttings are held in suspension longer and do not tend to settle out filling the hole or cause testing to be conducted in unusually heavy muds. A disadvantage of this procedure is that the materials in the upper portion of the hole are exposed for a longer period of time, during which they may tend to soften and cave. Also if the equipment becomes stuck and is lost while testing at depth, data for the upper materials may not be obtained unless a back-up anchor is available.

The converse is true when starting the tests at the ground surface. This is advantageous when the surficial material is soft, sensitive, or unstable. However, while this testing is being conducted, the suspended cuttings in the drill fluid have a chance to settle and create bridges at depth. 
Conditions of marginal borehole stability require a program of combined drilling and testing. After the sensor holes are drilled and cased, the anchor hole is drilled for the full test diameter to a depth of about 50 to 60 feet. Drilling is conducted in the morning and testing is performed in the afternoon, starting at the bottom and working to the surface. This operation is then repeated for the next 50- to 60-foot interval the next day and each following day until testing is completed to the full planned depth. With this testing sequence, borehole disturbances are minimized and the walls of the uncased anchor hole are left exposed for shorter periods of time. Also, the time during drilling can be used to clean, repair, and replace equipment as needed.

In any testing sequence, the sensors are usually lowered to the test depth first to determine if there are bridges or obstructions in the uncased sensor holes. Obstructions are generally dislodged or removed by jetting with water through a 3/4- or 1-inch plastic pipe inserted in the hole. Additional rigidity of the flushing pipe is achieved by attaching this pipe to the $1 / 2$-inch diameter steel rods used to lower the sensors. The combined jetting action and an up-down chopping action by manually raising and lowering the rods, can break bridges, stir up dense or heavy zones, and wash out this undesirable material. This operation can usually be conducted without having to move the drilling rig. Once the hole is cleaned, the sensors can again be placed on the rods and lowered to the desired test depth.

The free field sensors may be manually placed in holes up to 200 feet deep. The sensor package weighs less than 3 pounds and the 10-foot long interconnecting $1 / 2$-inch diameter steel rods used for lowering the sensors are made of relatively lightweight conduit pipe. In all tests the sensors are positioned against the soil wall or casing side at a point closest to the anchor. The position of the sensor is verified through orientation of the pin connections of the conduit rods.

Coupling of each sensor is achieved by inflating the rubber packer holder with compressed air or nitrogen. Firm coupling is verified by manually pulling or pushing on the interconnecting rods. During testing, the rods are left free standing above the 
ground surface, supported entirely by the coupled sensor. This provides a simple monitor of the coupling effectiveness. If the coupling becomes loose, the rods would drop several inches and catch an enlarged horizontal clamp on the top of either the ground surface or casing.

Once the free-field sensors are in position, the anchor and hammer system is lowered on drill rods to the prescribed test depth by the drilling rig and coupled to the walls of the boring.

The hydraulic anchor is expanded and coupled to the borehole walls by gradually increasing the hydraulic pressure in the 25 -ton ram until a stable value is reached. Coupling of the anchor assembly is checked both initially and during the test by measuring the jacking pressure and the vertical slip between the ram and yoke. As discussed in Section 4.1, these values are required to determine the diameter of the anchor and the resulting radial stress on the boring. Optimum coupling is essential as too high or low a pressure can affect the strains and the clarity of the signal generated (SW-AA, 1975a). The number of strokes applied to the hydraulic hand pump and the general resistance to pumping provides another index of the increasing soil resistance to jacking forces. In relatively competent soils, jacking pressures of 5,000-6,000 psi are common. In the softer soils, 3,000 psi is rarely achieved.

The pneumatic anchor is expanded and coupled to the borehole walls using compressed air or nitrogen. Typically, a pressure of 200 to 450 psi will achieve satisfactory results. As presently designed, it is not possible to determine the expanded diameter of the anchor and the corresponding stress applied to the boring. However, as explained in Section 5.1, it is possible to estimate both parameters within reasonable accuracy, knowing the general size of the hole and the pressure/diameter change relationship. The optimum pressure for coupling is obtained by trial and error. Air is added to the packer in increments of $50 \mathrm{psi}$ and coupling is checked by pushing slightly on the rods with the drill rig or by resting the weight of the rods on the assembly. 
Downward movement of the rods indicates inadequate coupling and another increment of pressure is applied. This operation is repeated until the system becomes fixed against the wall. A trial impact is then applied to check the adequacy of the coupling. High particle velocity amplitudes and a distorted record taken at the anchor and low free field amplitudes measured at the first hole will indicate poor coupling. The pressure is then increased until clear records are obtained.

When adequate coupling is achieved, another trial impact is applied to the system. Velocity time histories are obtained for each of the three sensor holes and for the transducer in the anchor assembly. These time histories are stored in the memory of the wave form recorder described in Section 4.2. Next, all four records are displayed in analog form on the screen of the oscilloseope, Figure 2.2. This allows the field engineer to determine if there is proper coupling of both the anchor and sensors, a clear impact of the hammer, and proper scales assigned on the recording equipment.

The adequacy of coupling is indicated in both the shape and amplitude of the velocity time history records. As shown in Figure 2.2, each record should have one major S-shaped pulse followed by one or two smaller S-shaped pulses having a frequency of about 100 to $200 \mathrm{hz}$. If the amplitude of the first pulse is small compared with the following pulses, then the coupling of the sensor or grouting of permanent casing may not be adequate. Small amplitude signals from the free field sensors will also indicate poor coupling of either the anchor or the sensors. Poor coupling is also indicated when the peak amplitude of one time history record is observed to be smaller in a close hole than in one at a more distant location. Wave characteristics appearing prior to the basic pulse indicate poor coupling due to air leakage from a sensor holder, a damaged geophone, or restriction of the hammer movement. On rare occasions, the hammer will drag on the side walls of the borehole or become bound to the guide rod when soil becomes packed in the annular space between the rod and hammer. 
Distortion of the anchor record alone usually indicates poor anchor coupling or a loosened anchor sensor. In these cases, very high amplitudes are obtained which usually exceed the capacity of the transducer. For the normal test frequencies, the transducer can usually reach maximum particle velocities amplitudes of about 20 or 30 inches per second. At these values, glitches (high-frequency pulses) appear on the record and generally indicate that the oscillating mass in the transducer has moved beyond its capability and has struck the end of the case.

Distortions in both anchor and free field records may also result if the guide rod (drill rod) for the hammer is not suspended from the anchor. If the guide rod is either pushing or pulling on the anchor assembly, extra high-frequency waves can be introduced onto the records. These minor distortions in the wave shape can influence the measured arrival times, especially if they occur near a peak.

Once the general wave shapes appear reasonable on the oscilloscope screen, the corresponding amplitudes are checked to verify that the closer sensors have the larger amplitudes. For stiff or dense soil, typical particle velocity amplitudes for a 150-pound hammer falling 6 inches will be about 15, 1, .5 and .1 inches per second for the anchor and the outlying sensor holes. While the actual amplitude will be variable and depend primarily upon the precise distances between holes and the soil stiffness or density; the ratio of the amplitudes between respective holes should be reasonably consistent for most soils. This ratio may be used as a base in the field to establish the adequacy of sensor coupling.

- Following this check, the recorder triggering device and time and amplitude scales are adjusted to obtain maximum resolution and full display of the entire event. The impact is then repeated and other records obtained the same way until four clear repeatable properly scaled time history signatures are obtained from one impact. Two or three tentative trials are usually sufficient to obtain a good test. The final records are reviewed to avoid having distortions occur on pertinent peaks and crossing points. If a distortion occurs that cannot be removed by repeating the test, then this last test is 
made a permanent record by first taking photographs of the oscilloscope display. Because portions of each signature may be expanded or the scale changed after the event, more than one photograph is of ten justified. The information is then recorded on a basic data sheet and in digital form on a computer compatible magnetic tape recorder. The photographs enable the overall signatures to be studied and assessed qualitatively while the digital records provide the necessary time and amplitude resolution needed in this test. The photographs also serve as a backup data source in the event of equipment malfunctions in the digital recording system.

The testing sequence consists of performing a series of six tests at 5-foot depth intervals. The sequence usually consists of three tests at two different energy levels. Different energy levels are achieved by varying the height of drop of one of the two hammers. For most soils, the drop commonly varies between six inches and two feet. Measured in the testing sequence are both the vertical and horizontal particle velocities at the sensors and the vertical particle velocities from geophones attached to two of the anchor plates. The horizontal particle velocity measurements are used to determine the compressional (P) wave velocity of the soil and the location of the water table. These also provide an independent check of the accuracy of the borehole survey. The reduction procedures for accomplishing this check are described in Section 2.2.

The two velocity records obtained at the anchor are used for determining average amplitudes and arrival times. Both of these records are affected by how the hammer strikes the anchor. Any tilt of the hammer at impact can cause larger particle velocity amplitudes, often by as much as 20 percent, and slightly faster arrival times (.1 to .2 millisecond) at one plate than the other. Use of only one anchor record decreases the accuracy of the computed velocity and strains at this station.

When the hydraulic anchor is used, the "slip" distance between the ram and yoke is measured and recorded at the start and finish of each test. This measurement and the jack pressure are used to compute the diameter of the hole and the magnitude of the horizontal jacking stress (Figure 4.3). Except in soft materials, this slip distance normally does not change significantly during testing. 
As the equipment is lowered to greater depths, the weight of the hydraulic hoses, the hydraulic fluid, and the electrical cable becomes excessive and cannot be handled manually. The hoses also stretch if pulled and elongates as pressure is applied. Keeping these hoses and cables tight above the anchor system is critical both during and following testing. Hose clamps have been satisfactorily used to attach the leads to the drill rods at 20 -foot intervals. If not secured, the leads may become pinched under the hammer during testing or in and around the anchor as it is collapsed or being moved up or down the hole. If the leads become entangled in the anchor, they may prevent its withdrawal.

The leads of the pneumatic anchor are sufficiently light that they may be secured by hand from the ground surface. The leads may become cut by the hammer or striker plate when working in a tight section of the boring. Cut air cables automatically cause the packer to deflate and retract providing an element of safety against its loss. A constant severing of the leads by the hammer may be resolved by replacing this section of the leads with steel brake line tubing. As shown in Figure 4.5, the sensor cable is also subject to damage since it passes by a number of working parts of the anchor. Damage to the cable and sensor has been minimal for all soils except gravels. Additional design changes are required in this anchor before it is suitable for testing gravel.

Following completion of testing, in-hole equipment is stripped down in the field, cleaned, oiled, and reassembled. The test data sheets, photographs, magnetic tapes and hole-measurement and survey records are returned to the office for data reduction. Much of the data is processed with a computer. Some graphical constructions are also required. Data-reduction procedures and pertinent parameters are described and identified respectively in Sections 2.2 and 2.3. 


\section{FIELD EQUIPMENT MAINTENANCE AND REPAIR}

Field equipment should be properly maintained at all times to expedite the testing program and to minimize drill rig stand-by time when repairs are required. Field repairs are quite costly since they not only involve the field engineer but also the drill crew and rig. Shutting down the operation for several days while the equipment is out for repair may easily add several thousand dollars to the job in stand-by costs. Therefore, it is important that not only equipment maintenance and check-out be a constant effort, but also that spare parts be available during testing.

To facilitate field repair, the in-hole equipment was designed to be easily stripped and repaired in the field using conventional hand tools. The following paragraphs discuss the major components, their weaknesses, and common problems encountered in their use.

\subsection{HYDRAULIC ANCHOR ASSEMBLY}

One of the most critical items requiring maintenance on the hydraulic anchor are the high-pressure hose leads. Since hydraulic pressure is used to expand and contract the anchor, a cut or damaged hose may prevent the anchor from retracting and possibly result in its loss. The most likely areas of hose damage are in the vicinity of the hammer. The hose may be pinched between the hammer and striking plate during the testing operation. The hose may also be bruised by the hammer when working in a tight hole.

Hose cuts which extend down to the reinforcing steel should be repaired immediately. Any commercially available electrical coating may be used which provides a strong, fast-drying outer seal. If cuts are left untreated, they will rust and eventually burst under the high hydraulic test pressures. 
One way of minimizing damage to the hose in the area of the hammer is to wrap each hose individually with electrical tape and then collectively tape the hoses and the sensor cables. This taping adds to the rigidity of the hoses, making them less likely to become tangled or pinched under the hammer. As testing progresses, damaged taped sections can be quickly and easily retaped. Taping a hose section for more than 10 feet should be avoided, as it will not be possible to change hoses or sensors without untaping the longer section. Replacement of damaged hoses or sensors can usually be accomplished in about 1 hour.

Entrapped air can develop in the hydraulic lines. Air may be purged from the system at the ground surface while the anchor is in the hole. Entrapped air has seldom been a problem in testing with this equipment.

The mechanical components of the anchor must be kept relatively clean and free of soil particles. Otherwise, accumulated material in the internal parts of the anchor may prevent proper closure of the plates. A procedure that has been used with success has been to remove the anchor from the hole for cleaning after every 50 feet of testing. At the surface, the anchor is expanded and cleaned by using a strong jet of water. Alternatively, the anchor may be cleaned by hand using a brush, 1-inch putty knife, and water. Disassembly of the anchor is usually not required.

Following the completion of testing at a site, the anchor should be disassembled, cleaned, inspected, and reassembled. Particular items requiring close inspection are the pins and arms connecting the anchor plate to the ram. The pins are made of a highstrength steel. They are brittle and break under the repetitive impact loads applied during the test. Although one fracture of the pin may not seriously affect the operation of the anchor, it should be replaced immediately. By keeping these pins cleaned and oiled, the anchor system can be completely disassembled, cleaned and reassembled in about 2 hours. This time can be doubled or tripled with rusted or corroded equipment. 
Also requiring close inspection are the nine arms connecting the anchor plates to the ram. These arms are the weakest component in the connecting system. The pin holes at the ends of the arms become stretched and distorted when jacking pressures exceeding 6,000 psi are used to retract the anchor. Higher pressures may break the arms at these locations. Normally, the anchor may be retracted using pressures of less than 2,000 psi. This pressure is often needed to break the bond between the plates and the soil. Use of higher pressures would indicate the presence of soil particles in the anchor. The anchor should then be removed from the hole, checked and cleaned as necessary.

Although it may not seem as strong as the other components, the yoke or hoisting system has been trouble free in testing the eleven sites. The yoke system has withstood large downward forces applied to the anchor in attempting to free it when stuck. Also, the yoke has withstood large upward forces when the anchor was raised through tight sections of the borings.

\subsection{PNEUMATIC ANCHOR ASSEMBLY}

Because this anchor functions similar to the hydraulic anchor, many of the maintenance procedures in Section 6.1 apply. The 1/4-inch plastic tubing used to supply the air to the packer is not a critical part since loss of air will cause the anchor to automatically retract. Plastic tubing is also inexpensive and easy to repair or replace in the field.

It is not necessary to clean the internal components of the pneumatic anchor as frequently as those of the hydraulic anchor. The pneumatic anchor is expanded by a central rubber packer and retracted by releasing pressure on the packer. In the retracted position, there is a void between the anchor plates and central body. Soil accumulating in this void does not seriously affect operation of the anchor since the packer may deform around these intrusions and expand the plates. To prevent an excessive soil accumulation, the anchor should be cleaned on a daily basis or after completing testing at a site. The anchor may be cleaned by hand or with a water jet. 
Other items requiring periodic inspection are the 18 stainless-steel cables and the high-strength bolts that attach the anchor plates to the central packer unit. Since the packer is used to expand the anchor, the only excessive loadings applied to the cables are the tensile forces needed to break the bond between outer plate surfaces and the soil walls after testing. This is best accomplished by raising the anchor as it directly tensions 12 of the 18 cables (Figure 4.4). These tensioned cables exert both an upward and an inward radial force on the anchor plates, which forces them to retract and pull away from the soil wall. Application of a downward force to an anchor pressed into the soil walls initially tensions only 6 of the 18 cables. However, if these cables fail, the remaining 12 will be tensioned. Frayed or severed cables should be replaced immediately.

A reasonable amount of care is required in handling the anchor to prevent bending of the thin vertical guide rod running through the hammer. This rod is designed for axial loading and not bending. A bent rod would restrict operation of the hammer.

After completing testing at a site, the metal parts of the anchor should be protected by painting or with a coating of vegetable oil. Petroleum oils should not be used on the anchor since they attack and rapidly deteriorate the rubber packer.

\subsection{SENSORS AND SENSOR HOLDERS}

Components of the sensor that may require field repair are the transducers, electrical cable leads and the inflatable rubber packers. Since these items are relatively inexpensive, several sets of spares should be carried in the field. The sensors should also be checked periodically to verify their proper operation.

Failure of a transducer is most likely the result of water leaking into the sensor case and creating an electrical short. This is more of a problem with the free field sensors which sometimes remain in the holes for the duration of testing. Since the anchor sensors receive the greatest impact loading, the sensor cases have a tendency to loosen from the anchor. In either case, transducers that have failed should be replaced with a spare sensor unit. 
Another item that may require field repair are the electrical cable leads for the anchor sensors. These leads may become occasionally nicked or damaged in the vicinity of the hammer or near the top of the anchor. Neoprene-coated electrical cable generally offers the most resistance to cutting and abrasion. Damaged leads may most easily be repaired by replacing both the leads and sensor with a spare, pre-assembled unit. Otherwise, the damaged cable area can be cut out and the two ends spliced back together. Splicing leads can usually be accomplished in less than 1 hour.

The electrical leads and air tubing for the free field sensors may become pinched or damaged if not kept above the sensor unit. This problem is minimized by securing the leads to the rods used to lower the sensors. Electrical tape has been satisfactorily used to secure the leads to the rods at 20 -foot intervals. Taping at 10-foot intervals at locations just above the bolts connecting the rods has been used where the rods were covered with mud.

Finally, the inflatable, $1 / 8$-inch thick rubber packers may require replacement if over-inflated or punctured. Recurrent puncture failures may be reduced by using a larger, 3/16-inch thick rubber packer.

The following procedures are used to check proper operation of the sensors. These tests are generally performed on all sensors, including replacement units, prior to the start of work at each site. The first check involves submerging the sensors and cables in water and lightly shaking the transducers. A shorted transducer or cut cable should show up immediately with this test. If all components seem satisfactory, then the next test is performed. This involves checking the geophone noise level on the oscilloscope. For this test, the signal is amplified several times above the smallest voltage that may be expected from the test ( 5 or 10 millivolts per division). Normally, a shielded cable will not show any significant noise at this level. The presence of significant noise requires either the repair or replacement of the sensor and cable. With the recording console, a faulty cable or transducer can usually be quickly detected. 
Periodically, all sensors should be compared or matched for consistency of response. This test is accomplished by taping all four sensors to a common support. The support is then tapped lightly and the resulting velocity signatures are recorded into the wave-form recorder and simultaneously displayed on the oscilloscope. The signals from the transducers are then greatly amplified for detailed checking for signal consistency. This test is then repeated by using lighter or sharper blows to cover both the amplitude and frequency ranges of interest. If any sensors are suspect in this test, they should be replaced.

\subsection{RECORDING EQUIPMENT}

The recording equipment for this test is sufficiently complex that field repair is impractical. Therefore, it is essential that this equipment be checked under simulated test conditions prior to actual use at each test site. The recording equipment, even though it is portable, was not designed for field use so special care is required in its shipment and handling. At the job site, the equipment should be cleaned and thoroughly rechecked with the source of $\mathrm{AC}$ power that will be used during the testing. Additional simulated test cases should be accomplished to recheck the equipment as early as possible such that action can be taken to repair equipment, if necessary. Tapes from these tests should be immediately shipped to the office to verify that they have no missing data blocks and can be easily read by the computer. A digital printout of all numbers in their proper format will usually enable a quick check of all records for errors.

Difficulties in reading the data tapes may be due to internal or external problems with the recording equipment. External problems may be due to the sensitivity of the equipment to the power source or temperature. These variables may be eliminated by checking the equipment in the field with an alternate power source or in a controlled temperature/humidity environment or both. In many cases, portable generators have not proven suitable power sources, while alternators, inverters using 12-volt batteries, 
utility-provided power have been satisfactory. If the equipment does not perform satisfactorily after these checks, then the problem is probably internal and would require sending the equipment out for repair.

In the testing program, the digital tape recorder has been the most sensitive portion of the data acquisition system. The main problem with this unit has been that the voltage output level has been lower than that which is needed to produce a strong signal on a tape. This problem is common among other recording units. The resulting tapes with their weak signal have been difficult to read on large computer systems. Even after having the recorder checked for this problem, special computer-processing techniques have been required in order to read $100 \%$ of the available data. Therefore, specifications of digital recorders should be carefully reviewed to be sure that the voltage output is adequate to produce digital tapes that are compatible with larger computer systems. It is also recommended that sample tapes be tested before final acceptance of any field system.

All electrical equipment in the console should be protected with dust covers when not in use. This includes tape heads, motors, and other mechanical components. 


\section{REFERENCES}

SW-AJA (1972)

"Soil Behavior under Earthquake Loading Conditions: State of the Art, Evaluation of Soil Characteristics for Seismic Response Analyses", A Joint Venture of Shannon \& Wilson, Inc., and Agbabian-Jacobsen Associates, Inc.

SW-AA (1974)

"Soil Behavior under Earthquake Loading Conditions: In Situ Impulse Test for Determination of Shear Modulus for Seismic Response Analyses, Progress Report", A Joint Venture of Shannon \& Wilson, Inc. and Agbabian Associates, June.

SW-AA (1975a)

"In Situ Impulse Test, An Experimental and Analytical Evaluation of Data Interpretation Procedures", A Joint Venture of Shannon \& Wilson, Inc. and Agbabian Associates, Aug., NUREG-0028, NRC-6.

SW-AA (1975b)

"Geotechnical and Strong Motion Earthquake Data from U.S. Accelerograph Stations, Vol. 1, Ferndale, Cholame, and El Centro, California", Sept., NUREG0029, NRC-6.

SW-AA (1976)

"Geotechnical and Strong Motion Earthquake Data from U.S. Accelerograph Stations, Vol. 2, Pasadena (CIT Millikan Library), Santa Barbara County Court House, Taft (Lincoln School Tunnel), and Hollister (Melendy Ranch Barn), California", June, NUREG-0029.

SW-AA (1977)

"Geotechnical and Strong Motion Earthquake Data from U.S. Accelerograph Stations, Vol. 3, Gilroy, Calif. (Gavilan College C6); Logan, Utah (Utah State Univ.); Bozeman, Mont. (Montana State Univ.); Tacoma, Wash. (County-City Bldg.); Helena, Mont. (Federal Bldg. and Carroll College), June (to be published).

Troncoso, J.H., Brown, F.R., \& Miller, R.P. (1977)

"In Situ Impulse Measurements of Shear Modulus of Soils as a Function of Strain", Sixth World Conference on Earthquake Engineering, New Delhi, Jan. Vol. 3, pp. 2316-2321.

Werner, S.D., and Van Dillen, D. (1977)

"Use of Analytical and Statistical Techniques to Assess In Situ Soil Test Procedures, Sixth World Conference on Earthquake Engineering, New Delhi, Jan., Vol. 3, pp. 2291-2302. 
Operation and Equipment Instructions for In Situ Impulse Test

A Joint Venture of Shannon \& Wilson, Inc. and Agbabian Associates

9. PERFORMING ORGANIZATION NAME AND MAILING ADDRESS (Include Zip Code)

Shannon \& Wilson, Inc. and

Agbabian Associates

1105 North 38 th Street

Seattle, Washington 98103

\section{DATE REPORT COMPLETED}

MONTH August 1 YEAA

DATE REPORT ISSUED

\begin{tabular}{l|l}
\hline MONTH & YEAA \\
November & 1979 \\
\hline
\end{tabular}

6. (Leave blonk)

8. (Loove blenk)

12. SPONSORING ORGANIZATION NAME AND MAILING ADDRESS (Include Zip Code)

U.S. Nuclear Regulatory Commission

Office of Nuclear Regulatory Research

Washington, D.C. 20555

10. PROJECT/TASK/WORK UNIT NO.

11. CONTRACT NO.

NRC $-04-76-200$

13. TYPE OF REPORT

PERIOD COVERED (Inclusive dows)

Technical report

14. (Leve blenk)

15. SUPPLEMENTARY NOTES

16. ABSTRACT (200 words or less)

This manual describes the test equipment and procedures for a new field test which determines the shear modulus of a soil deposit at strain levels equivalent to those experienced during actual earthquakes. Results from this test are typically used as input parameters to response analyses for evaluating local soil effects during earthquake shaking. The limitations of the test are also discussed. 